\title{
INVESTIGATION OF MICROALGAE GROWTH KINETICS USING COAL-FIRED FLUE GAS AS A CARBON SOURCE
}

\author{
A Thesis \\ Presented to \\ The Faculty of California Polytechnic State University, \\ San Luis Obispo
}

\author{
In Partial Fulfillment \\ of the Requirements for the Degree \\ Master of Science in Engineering, \\ Specialization in Bioengineering
}

by

Bryan Daniel Brooker

June 2011 
(C)2011

Bryan Daniel Brooker

ALL RIGHTS RESERVED 


\section{COMMITTEE MEMBERSHIP}

TITLE:

INVESTIGATION OF MICROALGAE GROWTH KINETICS

USING COAL-FIRED FLUE GAS AS A CARBON SOURCE

AUTHOR: $\quad$ Bryan Daniel Brooker

DATE SUMBITTED: June 2011

COMMITTEE CHAIR: Dr. Ilhami Yildiz

COMMITTEE MEMBER: Dr. Brian Hampson

COMMITTEE MEMBER: Dr. Robert Crockett 


\begin{abstract}
Investigation of Microalgae Growth Kinetics using Coal-Fired Flue Gas as a Carbon Source Bryan Daniel Brooker
\end{abstract}

Energy related carbon dioxide $\left(\mathrm{CO}_{2}\right)$ emissions make up the majority of the United States' greenhouse gas emissions. Emissions must be alleviated to reduce the effects of global climate change. Microalgae cultivation sequesters $\mathrm{CO}_{2}$ while producing biomass. Algal biomass can provide a renewable feedstock for biofuel and electricity production, and ingredients for pharmaceuticals, nutraceuticals, pigments and cosmetics. Utilizing microalgae to mitigate $\mathrm{CO}_{2}$ emissions encourages energy independence by providing a feedstock for biofuels and offers other potentially profitable avenues for the uses of biomass. This study focused on investigating the algal growth kinetics of microalgae cultivated with artificial coal-fired flue gas.

Two algal strains, Chlorella vulgaris and Tetraselmis sp. were cultivated in lab scale photobioreactors to assess the feasibility of using flue gas as a carbon source for microalgae growth. The microalgae growth kinetics were compared between flue gas and pure $\mathrm{CO}_{2}$ treatments for each algal strain. Both microalgae species were able to grow under flue gas dosing. The differences in growth characteristics for Chlorella were statistically insignificant between the two gas dosing treatments. Tetraselmis yielded identical maximum specific growth rates among the two gas treatments, while the biomass production was greater using $\mathrm{CO}_{2}$. At a 95\% confidence interval, the difference in biomass production between the gas treatments ranged from 45 to $225 \mathrm{mg} / \mathrm{L}$. The decrease in biomass production for Tetraselmis was the only sign of growth inhibition from flue gas. Overall, Chlorella vulgaris and Tetraselmis sp. are capable of fixating $\mathrm{CO}_{2}$ from coal-fired flue gas. 


\section{ACKNOWLEDGEMENTS}

First and foremost I would like to thank my friends and family for supporting my college endeavors with excitement and encouragement. Without your support I would not be where I am today. My gratitude extends to my colleagues, professors and Cal Poly administrative staff for their continual support throughout the duration of this project.

I am especially thankful for Dr. Ilhami Yildiz, not only providing me with the opportunity to work on a collaborative, multidisciplinary project, but for inspiring me with his enthusiasm and demand for quality work.

I am grateful for Dr. Brian Hampson's creative insights, emphasis on aseptic techniques and of course brewing great IPA together. I thank Dr. Yarrow Nelson for his excellent teaching of biochemical engineering, which ultimately secured my interest in the field of biological engineering. I am honored by Dr. Robert Crockett's support of my general engineering curriculum and found extreme value from his applied teaching of project management and entrepreneurship.

This project would have been left incomplete if it had not been for David Laiho and his assistance with Praxair. Dave, your help has been much appreciated. Kathy Daniels and Virgil provided endless assistance within the BRAE department and my thanks and praise go out to both of them. George Vellucci, and Diana Durany offered their time and I am very thankful for their laboratory support and analysis execution. 


\section{TABLE OF CONTENTS}

LIST OF TABLES ......................................................................................................................

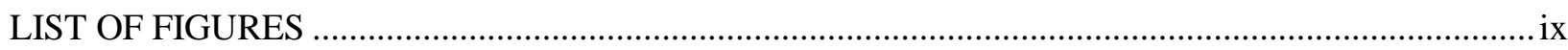

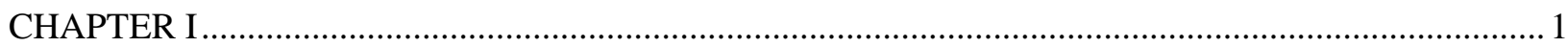

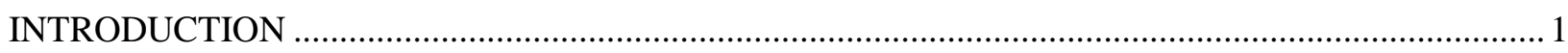

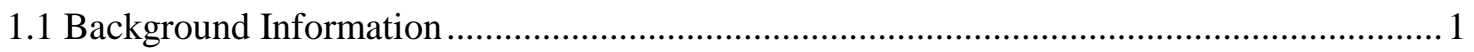

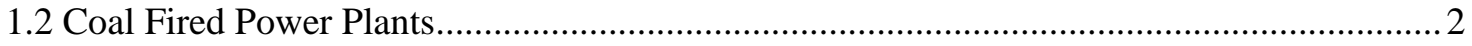

1.2.1 Flue Gas Characteristics ..................................................................................

1.3 Greenhouse Gas Regulation.......................................................................................

1.4 Present Carbon Capture and Storage Methodology ………………………………….........

1.5 Carbon Capture and Storage Alternative: Microalgae Cultivation ......................................... 5

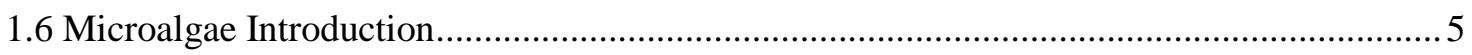

1.6.1 Growth Requirements ..................................................................................

1.6.2 Light "Photo" Requirements ....................................................................................

1.6.3 Nutrient Requirements ........................................................................................

1.6.4 Environmental Requirements.............................................................................

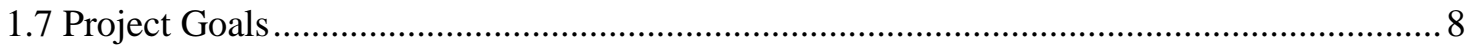

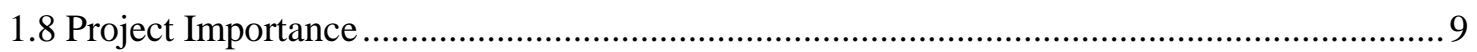

1.9 Experimental Strategy ………………………………………………………. 10

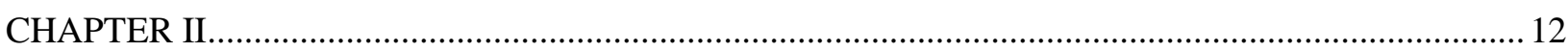

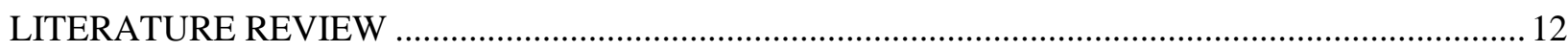

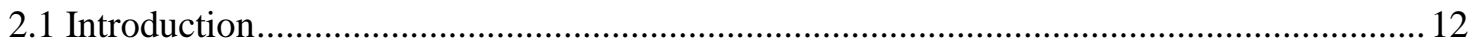

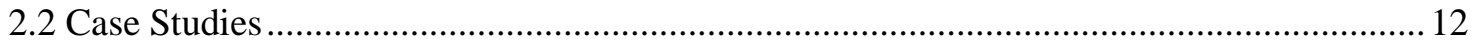

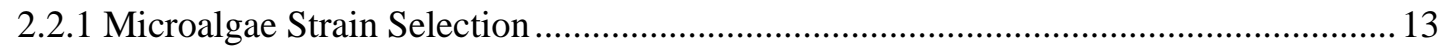

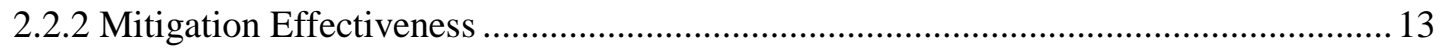

2.2.3 Nitrogen Oxides as a Nitrogen Supply ................................................................... 14

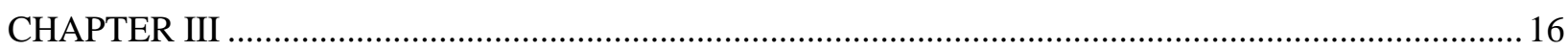

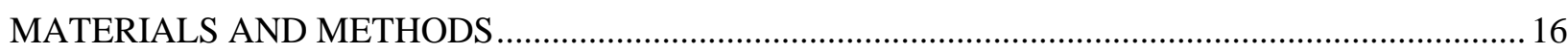

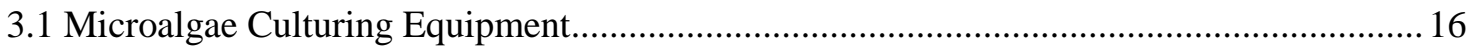

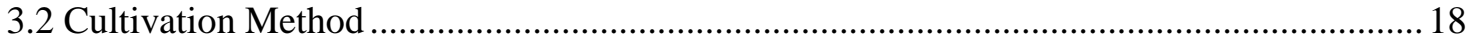

3.2.1 Maintaining Inoculum...................................................................................... 19

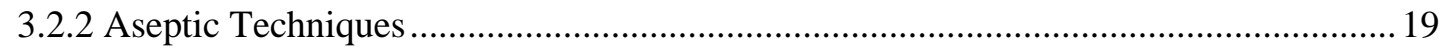

3.2.3 Inoculation Ingredients ......................................................................................2 


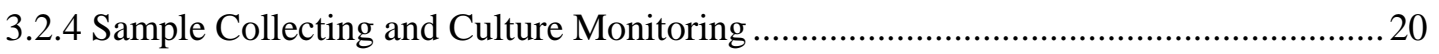

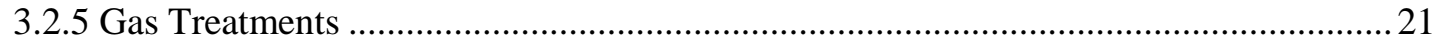

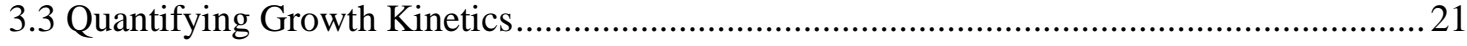

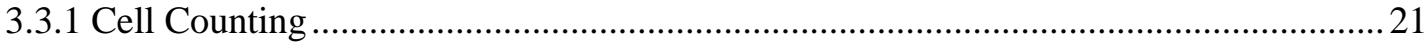

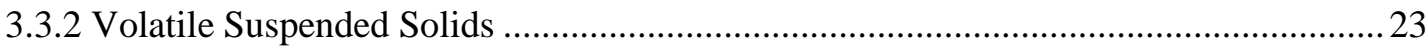

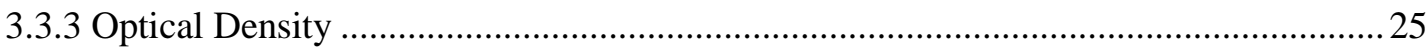

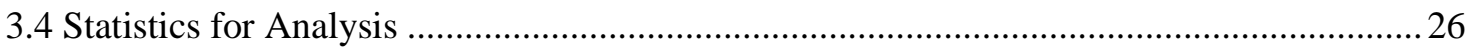

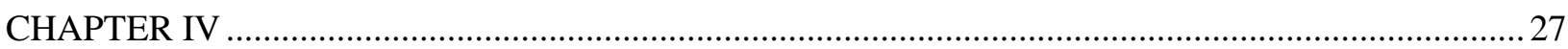

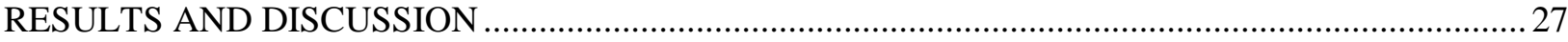

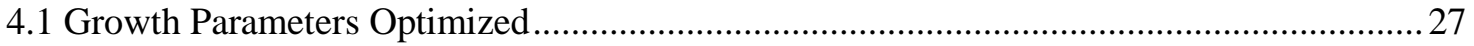

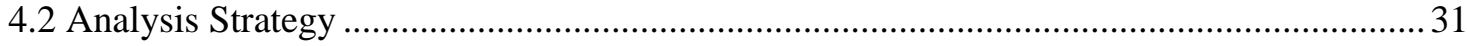

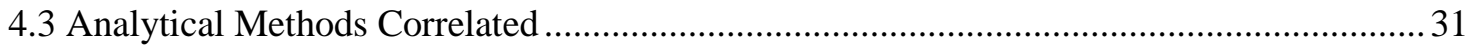

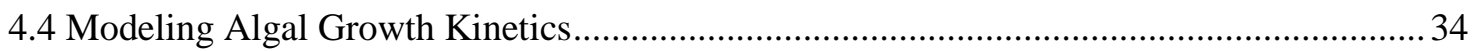

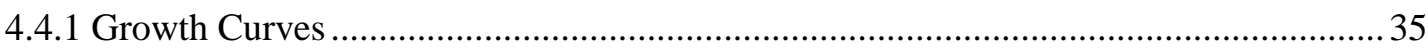

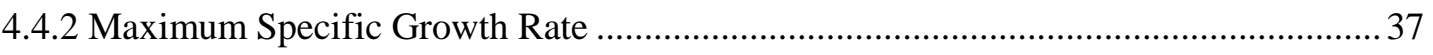

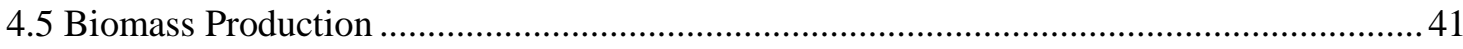

4.6 Inferences Based on Two Sample Populations ................................................................. 41

4.6.1 Cell Count Analysis ................................................................................................. 42

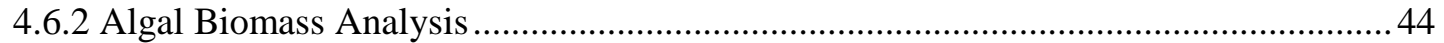

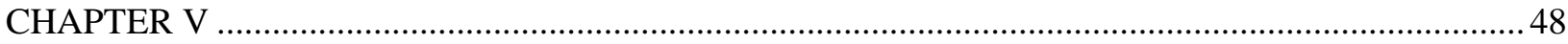

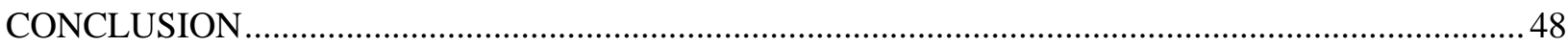

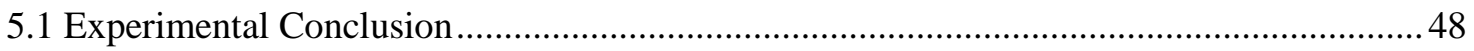

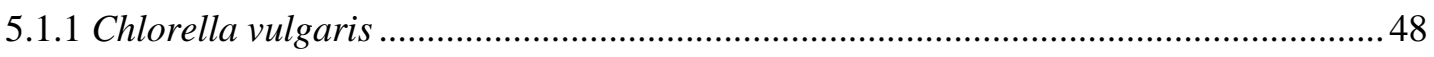

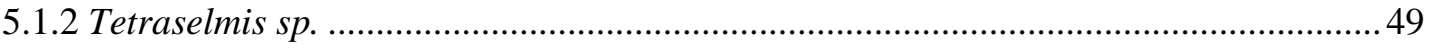

5.2 Recommendations for Further Research ........................................................................ 49

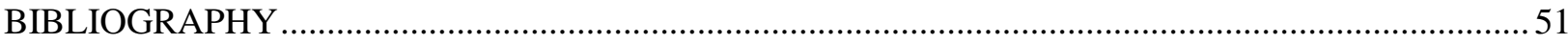




\section{LIST OF TABLES}

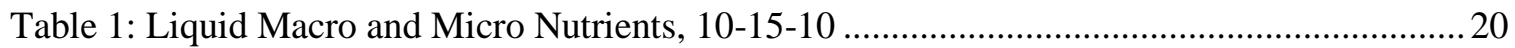

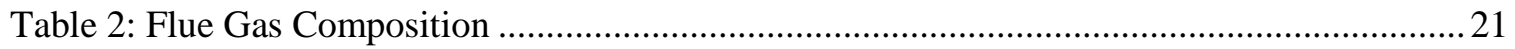

Table 3: Summarized relationship between cells $/ \mathrm{mL}$ and percent transmittance ..........................34

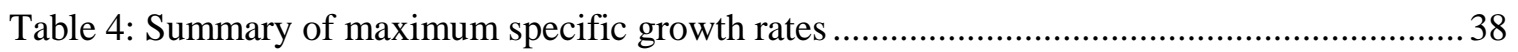

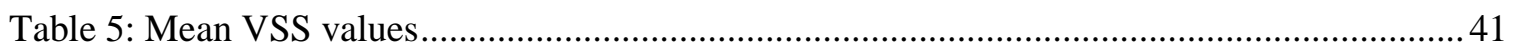

Table 6: Normality test for maximum specific growth rate data ................................................. 42

Table 7: Testing the difference of growth rates between gas dosing treatments ........................... 44

Table 8: Normality test for biomass produced from VSS measurements ................................... 45

Table 9: Testing the difference in algal biomass production between gas dosing treatments ....... 46 


\section{LIST OF FIGURES}

Figure 1: Carbon dioxide emissions by coal combustion, 2009 (Adapted from EIA, 2009)........... 1

Figure 2: Geological carbon storage (Global CCS Institute, 2010) ............................................

Figure 3: Optimizing growth inputs to maximize population.................................................... 7

Figure 4: Number of samples for one growth trial using a split plot experimental design ............ 10

Figure 7: Typical batch culture growth curve (Adapted from Shuler and Kargi, 2002)............... 18

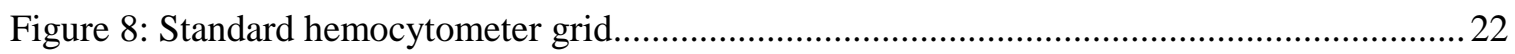

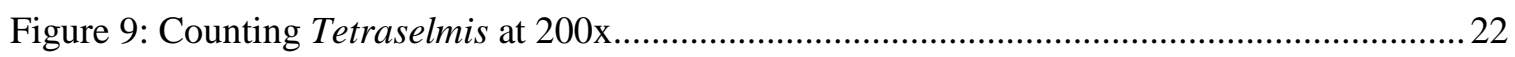

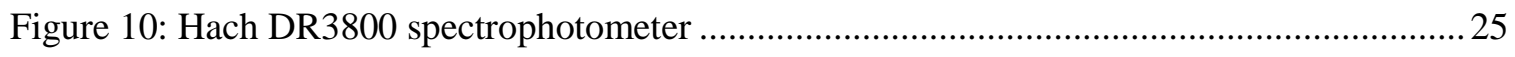

Figure 11: Chlorella and Tetraselmis mean temperature distribution from all growth trials ........28

Figure 12: Chlorella and Tetraselmis mean $\mathrm{pH}$ distribution from all growth trials ....................29

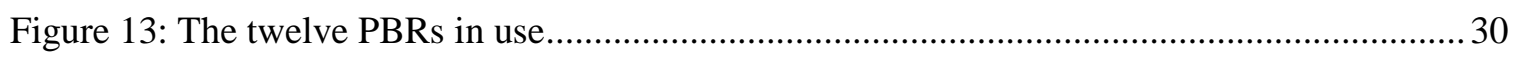

Figure 14: Correlation between analytical methods for Chlorella grown with $\mathrm{CO}_{2} \ldots \ldots \ldots \ldots \ldots \ldots . . . . . .32$

Figure 15: Correlation between analytical methods for Chlorella grown with flue gas................ 32

Figure 16: Correlation between analytical methods for Tetraselmis grown with $\mathrm{CO}_{2} \ldots \ldots \ldots \ldots \ldots . . . . .33$

Figure 17: Correlation between analytical methods for Tetraselmis grown with flue gas ............33

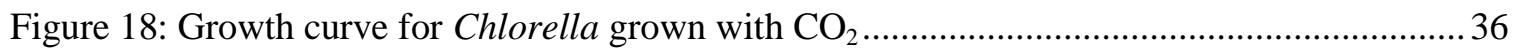

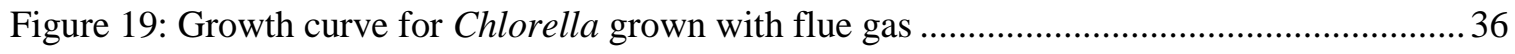

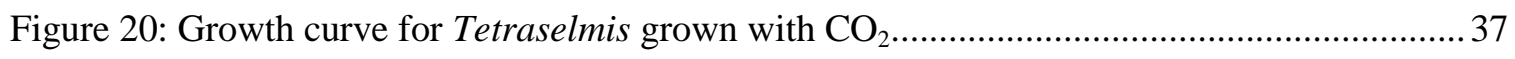

Figure 21: Growth curve for Tetraselmis grown with flue gas ................................................. 37

Figure 22: Maximum specific growth rate determination for Chlorella grown with $\mathrm{CO}_{2} \ldots \ldots \ldots \ldots . . . .39$

Figure 23: Maximum specific growth rate determination for Chlorella grown with flue gas........ 39

Figure 24: Maximum specific growth rate determination for Tetraselmis grown with $\mathrm{CO}_{2} \ldots \ldots . . .40$

Figure 25: Maximum specific growth rate determination for Tetraselmis grown with flue gas ... 40

Figure 26: Maximum specific growth rate data normality test for Chlorella $\mathrm{CO}_{2} \ldots \ldots \ldots \ldots \ldots \ldots \ldots . . . . . . . . .43$

Figure 27: Normality test for biomass produced data on Chlorella grown with $\mathrm{CO}_{2} \ldots \ldots \ldots \ldots \ldots \ldots . . . . .45$ 


\section{CHAPTER I}

\section{INTRODUCTION}

\subsection{Background Information}

In 2009 the United States anthropogenic greenhouse gas (GHG) emissions totaled to 6,600 million metric tons of carbon dioxide equivalent (EIA, 2009). Energy related carbon dioxide $\left(\mathrm{CO}_{2}\right)$ emissions make up the majority of total GHG emissions at approximately $82 \%$ of the total emissions. Within the energy sector, coal utilization contributes $35 \%$ of $\mathrm{CO}_{2}$ emissions as seen in Figure 1. Electricity production from coal fired power plants make up $93 \%$ of the total coal derived emissions, resulting to approximately 1,750 million metric tons of $\mathrm{CO}_{2}$ emitted in 2009 from the combustion of coal (EIA, 2009).

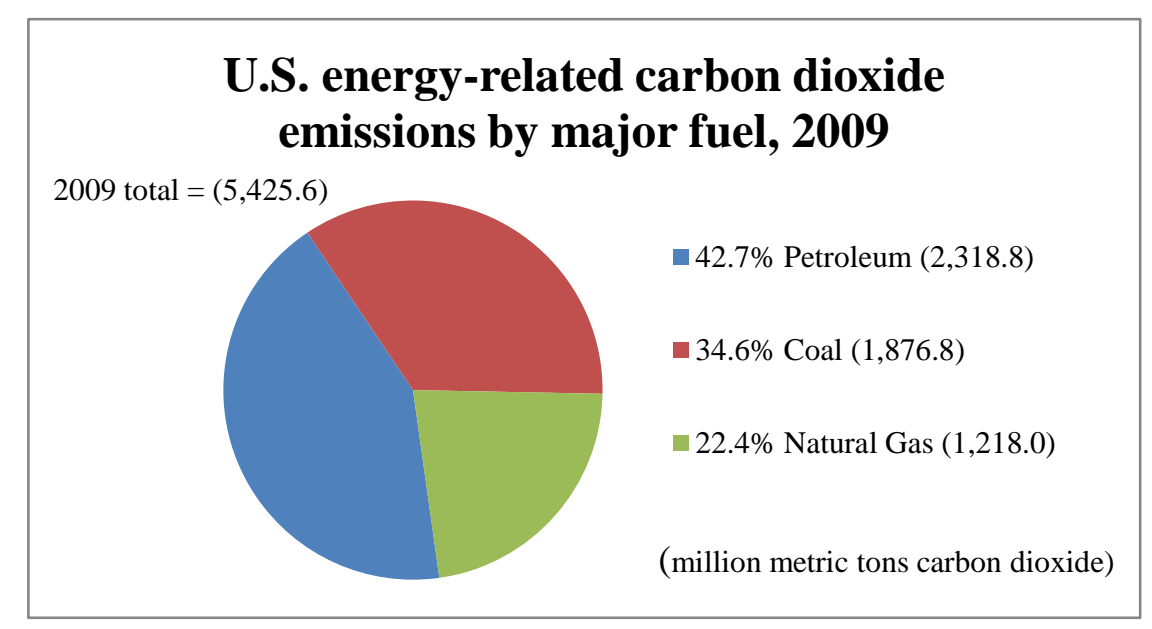

Figure 1: Carbon dioxide emissions by coal combustion, 2009 (Adapted from EIA, 2009)

Global GHG emissions from human activities are the driving force for climate change and the evidence of global climate change is indisputable (IPCC, 2007). Carbon dioxide is the dominate GHG and $\mathrm{CO}_{2}$ emissions have steadily risen since the industrial revolution, and are projected to increase globally by $1.3 \%$ per year (International Energy Outlook, 2010). Therefore, emission mitigation strategies must be implemented to reduce $\mathrm{CO}_{2}$ emissions and slow the effects of global climate change. 


\subsection{Coal Fired Power Plants}

Currently, coal provides about one half of all electricity generated in the United States (DOE, 2011). To sustain the United States electric energy demand, fossil fuel will continue to be used as an energy resource. One quarter of the global coal reserves are located in the United States ensuring the prolonged usage of coal as an energy resource. The combustion of coal releases an assortment of toxic gases into the atmosphere. Such gases are commonly known as flue gases, and include carbon dioxide $\left(\mathrm{CO}_{2}\right)$, nitrogen oxides $\left(\mathrm{NO}_{\mathrm{x}}\right)$, sulfur dioxide $\left(\mathrm{SO}_{2}\right)$ and particulate matter (PM; DOE, 2011).

\subsubsection{Flue Gas Characteristics}

The typical constituents of coal fired flue gas are $80 \%$ nitrogen, 10-15\% carbon dioxide, 5-10\% oxygen, 100-150 ppm nitrogen oxides, 300-500 ppm sulfur dioxide and approximately 50 $\mathrm{mg} / \mathrm{m}^{3}$ particulate matter (Oilgae, 2011). The precise flue gas composition depends on the type of coal being burned and the combustion characteristics.

Carbon dioxide is the primary GHG responsible for global warming. $\mathrm{CO}_{2}$ has become the basis for determining the global warming potential of other GHGs. The sheer quantity of $\mathrm{CO}_{2}$ emissions has made $\mathrm{CO}_{2}$ the most important GHG in need of a sequestration mechanism.

Nitric oxide (NO) and nitrogen dioxide $\left(\mathrm{NO}_{2}\right)$ are known as $\mathrm{NO}_{\mathrm{x}}$ because the two gases cycle between each other in the atmosphere. NO can oxidize in the presence of ozone $\left(\mathrm{O}_{3}\right)$ forming $\mathrm{NO}_{2}$. $\mathrm{NO}_{2}$ in turn can be reduced back to $\mathrm{NO}$ by photolysis (Sawyer et al., 2003). Due to the constant transformations between $\mathrm{NO}$ to $\mathrm{NO}_{2}$, a steady state concentration is reached with $\mathrm{NO}$ as the dominant species. At high temperature conditions, those similar to coal combustion, the thermodynamics favor the formation of NO. Therefore, typical combustion exhaust streams contain $90 \%$ NO (Ozkan et al., 1995). $\mathrm{NO}_{\mathrm{x}}$ has been linked to the formation of acid rain and photochemical smog (DOE, 2011). 
The consequences of emitting GHGs include global climate change, acid rain, smog and ozone depletion. Seeing that coal will continue to be used for electricity generation and GHG emissions must be alleviated to reduce the effects of global climate change, methods need to be developed and implemented for GHG abatement.

\subsection{Greenhouse Gas Regulation}

The U.S. Environmental Protection Agency (EPA) requires annual reporting of GHGs by specified sources, usually power plants. Known as the Mandatory Reporting of Greenhouse Gases Rule 74 FR 5620, this mandate requires industries to report their emissions in an attempt to accurately monitor the United States' GHG emissions (EPA, 2011). Although this mandate records GHG emissions, it does not regulate the quantity of GHGs emitted.

Carbon trading has been proposed, and would place a "cap" or upper limit on the amount of pollutants emitted (EPA, 2009). The cap is set lower than the historical emissions in an effort to decrease GHG emissions. Carbon trading would encourage emission abatement strategies because emissions exceeding the pollutant allowance would be fined. With carbon trading likely to become a reality, industries will be forced to buy additional allowances for their GHG emissions or invest in mitigation mechanisms.

In 2010 the United Nations Framework Convention on Climate Change announced their global atmospheric $\mathrm{CO}_{2}$ concentration cap at 450 parts per million (ppm), although this goal is a non-legally binding agreement (Global CCS Institute, 2010). To achieve a stable atmospheric $\mathrm{CO}_{2}$ concentration of $450 \mathrm{ppm}$, GHG emissions must be reduced by $80 \%$ (Stern, 2007; Global CCS Institute, 2010). Recalling that energy-related emissions accounted for $82 \%$ of total emissions in 2009, such a reduction would require energy sector emissions to be eliminated (Global CCS Institute, 2010). 


\subsection{Present Carbon Capture and Storage Methodology}

Currently, the method of carbon capture and storage (CCS) is to inject $\mathrm{CO}_{2}$ into geologic formations. CCS entails three distinct steps: carbon isolation, transportation and storage (DOE, 2011). Carbon isolation is achieved through various separation techniques isolating the $\mathrm{CO}_{2}$ from the flue gas. Then the $\mathrm{CO}_{2}$ is compressed and transported to the storage site. Long term carbon storage sites include geologic formations such as oil and gas reservoirs, methane coal beds, and saline formations as illustrated in Figure 2 (Global CCS Institute, 2010). The main goals in pumping $\mathrm{CO}_{2}$ into geologic formations are to 1) store $\mathrm{CO}_{2}$ while maintaining the environmental integrity of the geologic formation and 2) enhance the recovery of hydrocarbons yielding valueadded byproducts. Pumping $\mathrm{CO}_{2}$ into oil and gas reservoirs can improve oil and gas recovery and is known as enhanced oil recovery (EOR; Global CCS Institute, 2010). Methane coal beds are used in a similar fashion to oil and gas reservoirs, and by pressurizing a coal bed with $\mathrm{CO}_{2}$ the methane is displaced for more efficient methane recovery. Saline formations are believed to have large carbon loading capacities making them a viable long term solution for carbon sequestration. However, saline formations lack the aspect of value-added byproducts found in EOR and enhanced methane recovery. The biggest hurdle remaining for saline formation sequestration is proving that this method is environmentally acceptable. Containing the carbon dioxide within the saline formation is of highest priority to guarantee that it does not permeate through the earths subsurface and ultimately contaminate groundwater. To fully illustrate the early stages of development for CCS, there are 234 globally recognized CCS projects, and 77 provide both capture and storage while only 8 of the 77 are in operation (Global CCS Institute, 2010). 


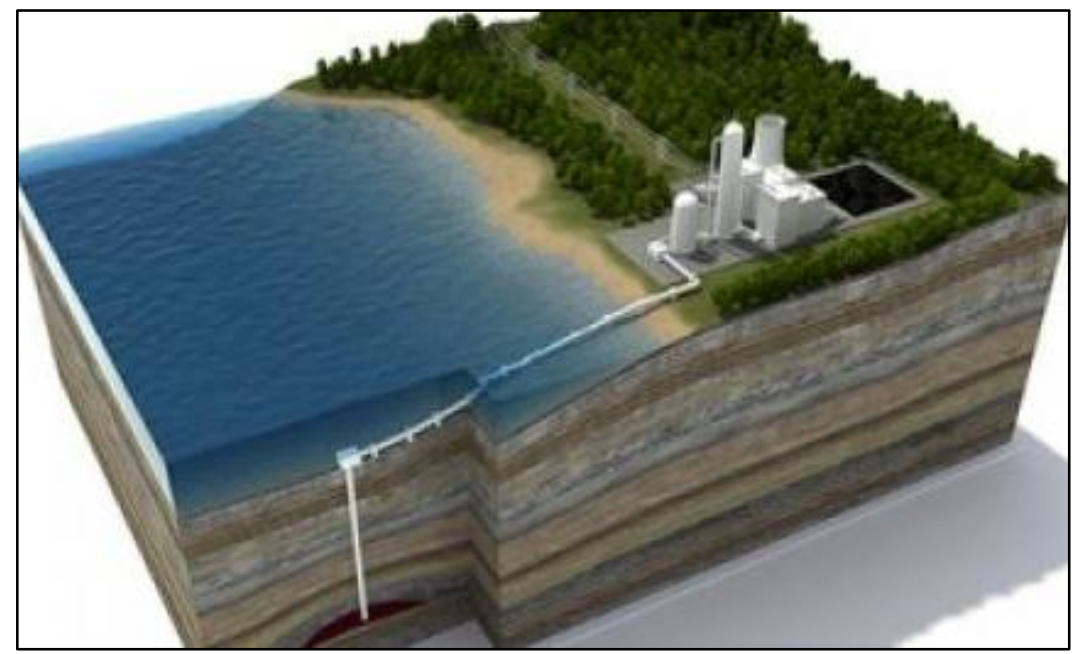

Figure 2: Geological carbon storage (Global CCS Institute, 2010)

\subsection{Carbon Capture and Storage Alternative: Microalgae Cultivation}

A viable alternative emission sequestration methodology is the cultivation of microalgae. $\mathrm{CO}_{2}$ fixation by microalgae grown outdoors is considered the best way to sequester $\mathrm{CO}_{2}$ because the solar energy utilization is much higher than that of terrestrial plants (Tapie and Bernard, 1988). As microalgae require $\mathrm{CO}_{2}$ to undergo photosynthesis, cultivating microalgae provides a living carbon sink that continually produces algal biomass. The biomass can be used for the production of biofuels, pharmaceuticals, nutraceuticals, pigments and cosmetics (Oilgae, 2011). Algal biomass can even be used as a fuel source to generate electricity. Microalgae cultivation has a large potential for successful GHG mitigation due to their rapid reproduction, versatile living conditions, and variety of applications to utilize the biomass. Similar to EOR, algal biomass provides the ingredients to produce value added byproducts. With the multitude of uses for biomass, potentially profitable markets exist to help offset the capital cost of implementing microalgae cultivation as a CCS method.

\subsection{Microalgae Introduction}

Algae are a diverse group of aquatic organisms. In the past blue-green algae and cyanobacteria were included in the classification of "algae". However cyanobacteria are 
prokaryotic organisms and lack a defined nucleus. Therefore, cyanobacteria/blue-green algae are now classified within the Bacteria domain. Algae are in the Eukarya domain due to a membrane enclosed nucleus, making them eukaryotic organisms. Algae exist as autotrophic and heterotrophic organisms. Autotrophs require $\mathrm{CO}_{2}$ as their exclusive carbon supply, while heterotrophs utilize organic carbon for energy, metabolism and growth (Sigee, 2005). Algae are subdivided into two classes- macroalgae and microalgae.

The largest and most complex forms of macroalgae are commonly known as kelp. Microalgae can exist as individual cells, in cell colonies, or as long filamentous chains (Sheeler and Bianchi, 1987). Microalgae cells range in size from a couple micrometers $(\mu \mathrm{m})$ to a few hundred micrometers. Microalgae lack features of higher order plants such as roots, stems, and leaves (Lee, 1999). Able to perform photosynthesis, microalgae produce oxygen while consuming atmospheric $\mathrm{CO}_{2}$. Photoautotrophic microalgae obtain sunlight for energy and $\mathrm{CO}_{2}$ provides the carbon supply, both of which are necessary for reproduction. Due to the abundant microalgae population, there is large domain of environmental conditions acceptable for cultivation. Microalgae growth is governed by light and nutrient supply, as well as the environmental parameters influencing growth for the specified algal strain.

\subsubsection{Growth Requirements}

Microalgae have a specific set of requirements for growth, similar to that of other photosynthetic plants. Basic inputs for microalgae growth include water, sunlight, nutrients and an acceptable range of environmental conditions specific to the algal species. Environmental conditions like temperature, $\mathrm{pH}$, salinity, and dissolved gases all affect the growth characteristics of microalgae. Growth inputs have an optimum range of supply, and providing the optimum growth conditions yields the largest algal population. Generally speaking, larger algal populations result to greater quantities of algal biomass. Figure 3 illustrates how each growth variable (gradient) has a range of influence which can be either too little, too great, or within an optimum 
range. Managing the algal growth variables to remain within an optimum range of tolerance produces the greatest amount of biomass, yielding the largest carbon consumption.

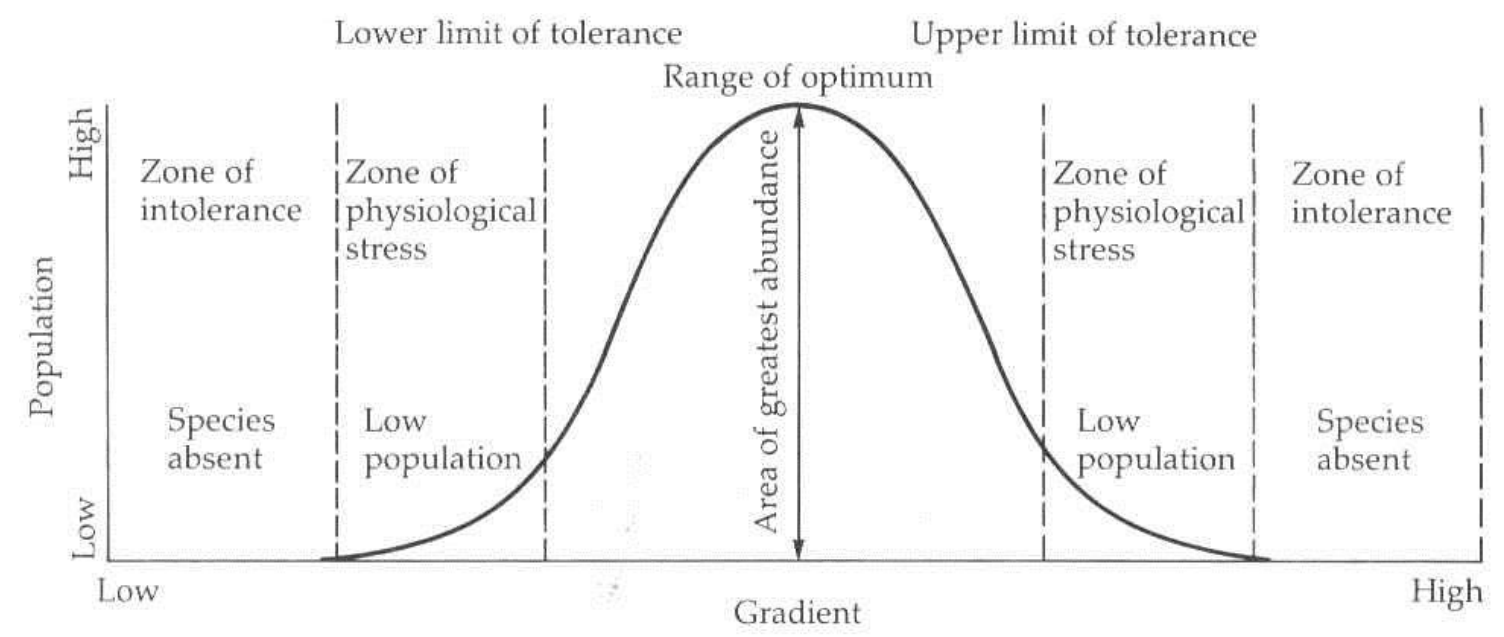

Figure 3: Optimizing growth inputs to maximize population

\subsubsection{Light "Photo" Requirements}

Microalgae require a light period as well as a dark period to grow, known as a photoperiod (South and Whittick, 1987). The light period allows photosynthesis to occur while the dark phase allows the algae to respire. The photosynthesis reaction is shown below as Equation 1. Chloroplasts absorb light energy, and in the presence of $\mathrm{CO}_{2}$ and water, convert the captured energy into potential chemical energy (Sheeler and Bianchi, 1987). In this way photosynthesis transforms light energy along with $\mathrm{CO}_{2}$ and water into chemical energy in the form of carbohydrates and releases oxygen in the process. During the dark phase, respiration follows the same equation proceeding in the opposite direction.

$$
6 \mathrm{CO}_{2}+6 \mathrm{H}_{2} \mathrm{O}+\text { light } \leftrightarrow \mathrm{C}_{6} \mathrm{H}_{12} \mathrm{O}_{6}+6 \mathrm{O}_{2}
$$

Equation 1

\subsubsection{Nutrient Requirements}

Carbon is an indispensable nutrient for the growth of microalgae. $\mathrm{CO}_{2}$ is a key ingredient driving photosynthesis and is the primary GHG to be sequestered. When $\mathrm{CO}_{2}$ is injected into 
water it becomes carbonic acid $\left(\mathrm{H}_{2} \mathrm{CO}_{3}\right)$, thus lowering the water $\mathrm{pH}$ (Sawyer et al., 2003). The following set of equilibrium equations illustrates how $\mathrm{H}_{2} \mathrm{CO}_{3}$ behaves in an aqueous solution and identifies the carbonic species that are consumed by microalgae according to the $\mathrm{pH}$.

$$
\begin{array}{cr}
\left.\mathrm{CO}_{2} \text { (gas }\right)+\mathrm{H}_{2} \mathrm{O}(\mathrm{aq}) \rightarrow \mathrm{H}_{2} \mathrm{CO}_{3}(\mathrm{aq}) & \text { Equation } 2 \\
\mathrm{H}_{2} \mathrm{CO}_{3} \leftrightarrow \mathrm{H}^{+}+\mathrm{HCO}_{3}^{-} & \text {Equation 3 } \\
\mathrm{HCO}_{3}^{-} \leftrightarrow \mathrm{H}^{+}+\mathrm{CO}_{3}^{2-} & \text { Equation 4 }
\end{array}
$$

Besides carbon, the next most important nutrients are nitrogen, phosphorous, and potassium. Nitrogen $(\mathrm{N})$, phosphorous $(\mathrm{P})$, and potassium $(\mathrm{K})$ are the fundamental macro nutrients required by all plants, and usually plant fertilizers are categorized by their N-P-K ratios. Various micro nutrients such as calcium, iron, magnesium, sulfur, zinc, and various trace elements are also necessary to fully satisfy the nutrient requirements of microalgae. Because microalgae are suspended in water, the nutrient availability is great, and therefore maintaining sufficient nutrient levels is essential for optimum algal growth.

\subsubsection{Environmental Requirements}

Environmental conditions play an important role governing the growth of microalgae. Environmental parameters such as temperature, $\mathrm{pH}$, salinity, and dissolved oxygen ultimately affect the success of algal cultivation. The microalgae population is composed of around 100,000 identified species, and currently 2,800 different strains are available for purchase (Sheehan et al., 1998; UTEX, 2011). Therefore, the optimum environmental conditions are specific to the individual algal strain.

\subsection{Project Goals}

The main purpose of this project was to investigate and evaluate the use of coal fired flue gas as a carbon source for microalgae cultivation. Lab scale photobioreactors were used to grow microalgae and demonstrate that microalgae cultivation provides a viable CCS method. Analytical methods were used to model the algal growth kinetics. Using the biomass produced 
and the maximum specific growth rate a comparison was drawn between flue gas and pure $\mathrm{CO}_{2}$ dosing for each algal strain. The purpose of this project was broken down into 4 specific project outcomes:

1) Confirm the feasibility of cultivating microalgae with flue gas as a carbon source

2) Maximize algal biomass production

3) Quantify microalgae growth kinetics

4) Analyze the growth kinetics among gas dosing treatments

\subsection{Project Importance}

Industrial emissions are becoming increasingly ascribed to global climate change as identified by the Intergovernmental Panel on Climate Change (IPCC). GHG emissions are beginning to be regulated and therefore methods for reducing emissions will be implemented. As said by the IPCC, all energy related emissions must be eliminated to effectively stabilize the atmospheric $\mathrm{CO}_{2}$ concentration at $450 \mathrm{ppm}$. Further, utilizing microalgae as a CCS method gives rise to a biofuel feedstock that could help the United States become independent of foreign oil. Overall, the importance of sustainability and environmental consciousness is greater than ever, and seeing that energy related emissions will not cease, the need to mitigate GHGs is unprecedented. Cultivating microalgae provides a biological mechanism for sequestering $\mathrm{CO}_{2}$ and provides a renewable feedstock for biofuels. This is of utmost value, the fact that one process, cultivating microalgae satisfies two prevalent global needs; the need to reduce $\mathrm{CO}_{2}$ emissions while producing a renewable feedstock for biofuels. Here the old saying, to kill two birds with one stone has never been more appropriate. 


\subsection{Experimental Strategy}

Two microalgae species were chosen for this experiment. One freshwater and one saltwater strain were selected for growth for the reason that power plants are located near bodies of water for cooling, whether it is fresh or salt water. The water body adjacent to the power plant would have to be used as growth medium to fulfill the large water demand for microalgae cultivation. Chlorella vulgaris was the chosen freshwater strain, and Tetraselmis sp. was the saltwater strain used. Originally, both algal strains were to be tested in 9 trials of week-long growth periods. Due to the financial constraints on the project only 3 trials were carried out. In addition, the growth period was reduced to 5 days. Using twelve lab-scale phtotobioreactors (PBRs), a spilt plot design was implemented to maintain consistency among gas treatments and growth trials. Therefore, both algal strains and both gas dosing techniques were applied for every growth trial. Figure 4 illustrates the split plot design incorporating two microalgae strains, Chlorella and Tetraselmis, and two gas dosing regimens. Pure $\mathrm{CO}_{2}$ dosing was the control variable for algal growth, while flue gas dosing was the variable of interest. The algal growth characteristics under flue gas dosing were compared to the algal growth characteristics exhibited by the control variable per algal species. Executing 3 growth trials with this experimental design yielded 9 replicates per algal strain for each gas treatment.

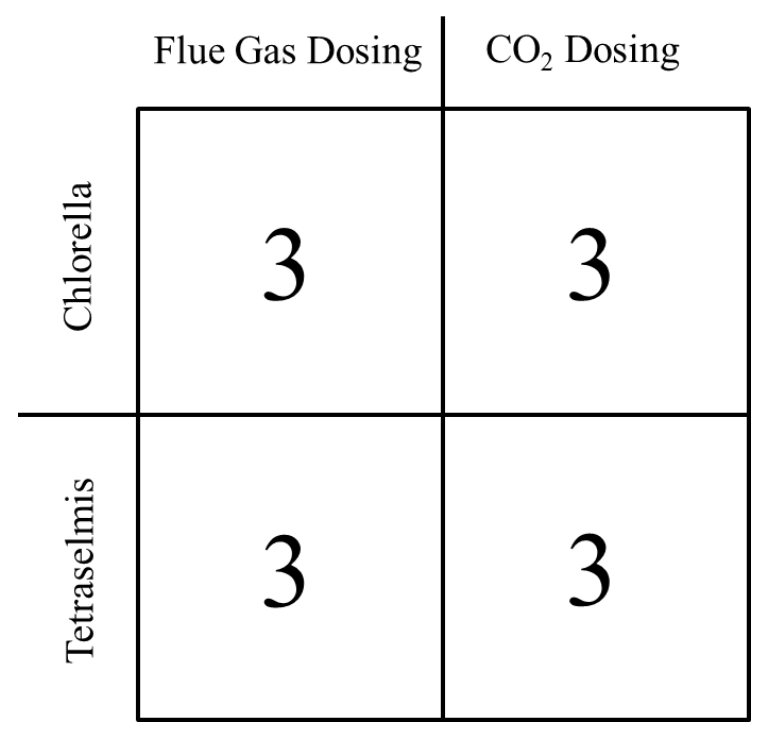

Figure 4: Number of samples for one growth trial using a split plot experimental design 
Each photobioreactor (PBR) configuration aimed to maintain optimum environmental conditions such as light influx, temperature and $\mathrm{pH}$. Setting these variables at the optimum level per algal species promoted the fastest reproductive rates and resulted in the largest carbon sequestering capacities. The photoperiod was the same for each algal strain. The temperature was controlled for Chlorella only due to its optimum temperature at $29^{\circ} \mathrm{C}$ (Mehlitz, 2009). Tetraselmis being the saltwater strain prefers cooler water and therefore Tetraselmis was subject to ambient temperature conditions. The $\mathrm{pH}$ was monitored and maintained at relatively constant levels by gas injection. Equal nutrient supplements were provided upon inoculation. Through these methods the variables effecting microalgae growth were isolated, effectively eliminating the influence on algal growth from such variables. Maintaining consistent environmental conditions allowed the variable of interest, flue gas dosing, to be compared against the control variable, $\mathrm{CO}_{2}$ dosing. The experimental design intended to maximize algal biomass production and confirm flue gas as a carbon substitute for algal cultivation. The hypothesis was to determine whether or not a statistically significant difference existed between microalgae grown with two different carbon sources, flue gas verse pure $\mathrm{CO}_{2}$. 


\section{CHAPTER II}

\section{LITERATURE REVIEW}

\subsection{Introduction}

Algal flue gas mitigation has been studied for the past couple of decades and poses as a viable biological mechanism to capture and utilize $\mathrm{CO}_{2}$. Using flue gas from various combustion processes as a carbon source for algal growth has been proven on a lab scale. Microalgae cultivation successfully assimilates $\mathrm{CO}_{2}$ from flue gas and can grow with minimal inhibition in the presence of $\mathrm{NO}_{\mathrm{x}}$ and $\mathrm{SO}_{\mathrm{x}}$ (Yoshihara et al., 1996; Doucha et al., 2005). Supplying flue gas for microalgae cultivation and $\mathrm{CO}_{2}$ fixation can occur in two ways, by direct flue gas injection or separating the $\mathrm{CO}_{2}$ from the exhaust stream. Isolating $\mathrm{CO}_{2}$ from exhaust streams is an unfavorable precursor for algal cultivation in terms of the energy and cost requirements to separate $\mathrm{CO}_{2}$. Direct flue gas injection into algal cultures brings arise to issues pertaining to the high temperatures of flue gas, and the presence of $\mathrm{NO}_{\mathrm{x}}$ and $\mathrm{SO}_{\mathrm{x}}$ (Madea et al., 1995). For this reason, microalgae strains tolerant to high temperatures and resilient to the presence of $\mathrm{NO}_{\mathrm{x}}$ and $\mathrm{SO}_{\mathrm{x}}$ have historically been sought to be cultivated as a biological mechanism to mitigate flue gas emissions. Previous studies have focused on identifying microalgae strains capable of withstanding direct flue gas injection, the effectiveness of $\mathrm{CO}_{2}$ mitigation (flue gas decarbonization), $\mathrm{NO}_{\mathrm{x}}$ serving as a potential nitrogen source for algal growth, and the economic analysis of implementing microalgae cultivation as a flue gas emission mitigation strategy.

\subsection{Case Studies}

The case studies highlighted for the investigation of this project were chosen to illustrate the progression of cultivating microalgae with flue gas. They are not the only studies pertaining to this area of research; however they represent the development of utilizing microalgae cultivation to mitigate flue gas emissions. 


\subsubsection{Microalgae Strain Selection}

In a report published by Maeda et al. (1995) titled, $\mathrm{CO}_{2}$ Fixation from the Flue Gas on Coal-fired Thermal Power Plant by Microalgae, the microalgae strain Chlorella sp. T-1 was identified as being able to grow under direct flue gas injection conditions. A series of growth treatments were performed to determine the algal resistance to temperature, $\mathrm{CO}_{2}, \mathrm{NO}_{\mathrm{x}}$ and $\mathrm{SO}_{\mathrm{x}}$ variations. Chlorella sp. $T-1$ was grown in $600 \mathrm{~mL}$ batch cultures and demonstrated resilience up to $40^{\circ} \mathrm{C}$. Algal $\mathrm{CO}_{2}$ resistance favored $10-50 \% \mathrm{CO}_{2}$ concentrations delivered at $0.5 \mathrm{~L} / \mathrm{min}$. The same concentration of $\mathrm{NO}_{\mathrm{x}}$ and $\mathrm{SO}_{\mathrm{x}}$ in flue gas, half the concentration, and double the concentration resulted in no effect on algal growth. Through this study Chlorella sp. T-1 was found to be a successful candidate for growth in severe environmental conditions such as those experienced by using flue gas as a carbon source for microalgae cultivation.

\subsubsection{Mitigation Effectiveness}

Using microalgae as a carbon fixer for flue gas emissions requires a high degree of $\mathrm{CO}_{2}$ mitigation efficiency if industrial implementation is to take place. Ultimately, microalgae must sequester a significant fraction of $\mathrm{CO}_{2}$ from power plant exhaust streams to effectively provide a mitigation strategy. Doucha et al. (2005) performed a study to determine the degree of $\mathrm{CO}_{2}$ mitigation or "flue gas decarbonization". In their publication titled, Utilization of Flue Gas for Cultivation of Microalgae (Chlorella sp.) in an Outdoor Open Thin-layer Photobioreactor they achieved $10-50 \% \mathrm{CO}_{2}$ consumption by microalgae grown in a $330 \mathrm{~L}$ photobioreactor. Their

photobioreactor was characterized by a $55 \mathrm{~m}^{2}$ culture surface area with an algal suspension thickness of $6 \mathrm{~mm}$. They further deduced that increasing the flue gas injection rate decreased the degree of $\mathrm{CO}_{2}$ mitigation. In a $\mathrm{CO}_{2}$ mass balance on flue gas containing $8 \% \mathrm{CO}_{2}$, the efficiency of microalgae $\mathrm{CO}_{2}$ biofixation was determined. Upon flue gas injection, half of the $\mathrm{CO}_{2}$ content in the flue gas was lost due to culture medium saturation. Of the remaining 50\%, approximately $10 \%$ was lost from suspension, resulting to $40 \%$ of the $\mathrm{CO}_{2}$ supplied within the flue gas to be 
utilized by the algal cells. This flue gas decarbonization efficiency was specific to the bioreactor design, algal strain used, and environmental parameters surrounding microalgae growth.

Novakovic et al. (2005) published their work titled, Air-Lift Bioreactors for Algal Growth on Flue Gas: Mathematical Modeling and Pilot-Plant Studies and demonstrated a greater carbon uptake efficiency. Thirty triangular air lift bioreactors were used for cultivation each with a volume of $30 \mathrm{~L}$. Flue gas was constantly administered into each bioreactor at a flow rate of 600$800 \mathrm{~mL} / \mathrm{min}$. They reported a $\mathrm{CO}_{2}$ removal efficiency of $82.3 \pm 12.5 \%$ on sunny days and $50.1 \pm$ $6.5 \%$ on cloudy days. Further, the biomass production was consistent with the carbon removal efficiency. The high decarbonization efficiency may have been due to the specialized bioreactor in operation; however it reveals that a carbon uptake efficiency of $80 \%$ is achievable.

\subsubsection{Nitrogen Oxides as a Nitrogen Supply}

Studies have been performed to determine whether or not $\mathrm{NO}_{\mathrm{x}}$ can provide a supplemental nitrogen source for microalgae growth. Nagase et al. (2001) explored the ways in which NO is utilized by microalgae. Their publication titled, Uptake Pathway and Continuous Removal of Nitric Oxide from Flue Gas using Microalgae assumed that two possible pathways existed. The first possible pathway being the oxidation of dissolved NO into nitrate or nitrite. The second pathway was direct diffusion of NO into the cells. The results concluded that little NO was oxidized in the culture medium, and therefore the majority of NO diffused into the algal cells.

The aforementioned study by Doucha et al. (2005) determined the effectiveness of Chlorella sp.to denitrify flue gas. About $10 \%$ of the $\mathrm{NO}_{\mathrm{x}}$ from the entering flue gas was able to be absorbed in the culture solution.

In a study conducted by Yoshihara et al. (1996) titled, Biological Elimination of Nitric Oxide and Carbon Dioxide from Flue Gas by Marine Microalga NOA-113 Cultivated in a Long Tubular Photobioreactor the effects of NO concentration, flow rate, and algal uptake of NO were 
investigated. A $4 \mathrm{~L}$ vertical column bioreactor was used to cultivate a marine microalga strain NOA-113. The optimum gas flow rate was $100 \mathrm{~mL} / \mathrm{min}$ causing a $51 \%$ elimination of NO. Approximately half of the NO supplied from the flue gas was consumed at NO concentrations of 100 and $300 \mathrm{ppm}$.

The denitrification of flue gas could potentially supply an additional nitrogen source for microalgae to grow. Although the works previously listed do not conclude the same reduction in $\mathrm{NO}_{\mathrm{x}}$ by microalgae, it is evident that $\mathrm{NO}_{\mathrm{x}}$ can be mitigated through microalgae cultivation. 


\section{CHAPTER III}

\section{MATERIALS AND METHODS}

\subsection{Microalgae Culturing Equipment}

Bioreactors have long been used for microbial growth and fermentation. The word photobioreactor (PBR) stems from the historical use of bioreactors in the biotechnology industry with the addition of "photo" implying the reactor itself is transparent allowing an influx of light energy. Photobioreactors (PBRs) served as the holding tank allowing algal growth and carbon fixation. Twelve vertical column Plankton Reactors (Aqua Medic, Plankton Reactor, Bissendorf, Germany) were used and for the remainder of this report will be called PBRs. Each PBR was a transparent plastic cylinder with a holding volume of $2.25 \mathrm{~L}$. A fluorescent light ( $18 \mathrm{~W}, 6700 \mathrm{~K}$, 1300 1m; Aqua Medic, Plankton Light Reactor, Bissendorf, Germany) provided the necessary light for photosynthesis to occur. As microalgae grow the $\mathrm{pH}$ of the algal slurry increases due to the consumption of the carbonic species present. By setting a $\mathrm{pH}$ target point, $\mathrm{CO}_{2}$ or flue gas was injected into the aqueous solution upon reaching the upper target value. The upper $\mathrm{pH}$ limit was set at 7.5 and 8.0 for Chlorella and Tetraselmis respectively. Injecting $\mathrm{CO}_{2}$ into the aqueous solution forms carbonic acid, thus lowering the $\mathrm{pH}$. Therefore, the $\mathrm{pH}$ was in constant balance between algal carbon fixation and gas injection. Twelve $\mathrm{pH}$ meters (Milwaukee, SMS 122, Romania) continuously monitored the $\mathrm{pH}$ of the algal solution. They were coupled with $\mathrm{CO}_{2}$ control valves (Red Sea, $\mathrm{CO}_{2}$ Magnetventil, Israel) which acted as the gas dosing solenoid, in essence maintaining a constant $\mathrm{pH}$ level by supplying the proper amount of carbon. Ambient air pumps (Fusion Quiet Power, 400, Taiwan) were used to continuously agitate the culture and keep the algal solution homogeneous. Digital thermometers (Coralife, ESU Reptile) monitored the aqueous solution temperature. Submersible heaters (Marine Land, Stealth Pro, China) were used for cultivating Chorella and were set at $30^{\circ} \mathrm{C}$. Ambient temperature conditions were sufficient for Tetraselmis as its optimum temperature was around $22^{\circ} \mathrm{C}$. Combining this set of cultivation 
equipment allowed the major growth variables to be controlled and maintained at constant levels. Keeping the temperature, $\mathrm{pH}$, and nutrient levels constant enabled the variable in question, the effect of direct flue gas injection to be investigated. Each PBR was accompanied by the same additional components to make twelve complete PBR sets as seen in Figure 5 and 6.

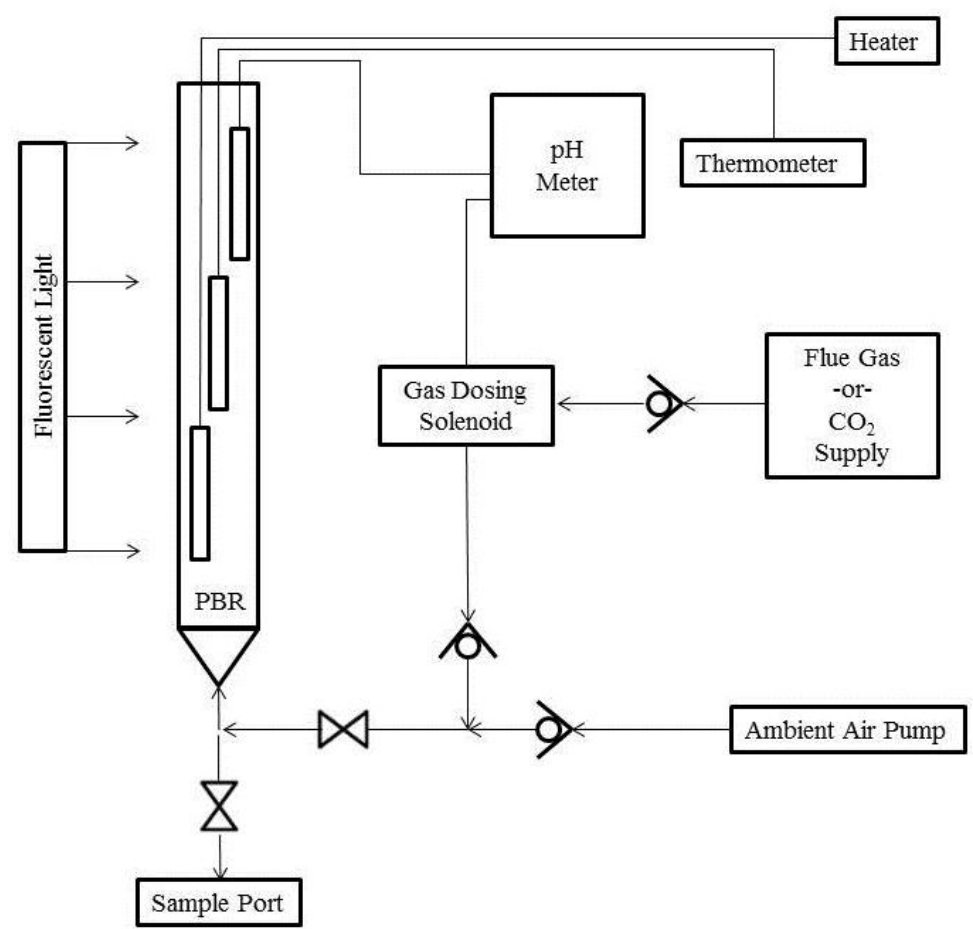

Figure 5: Laboratory PBR schematic

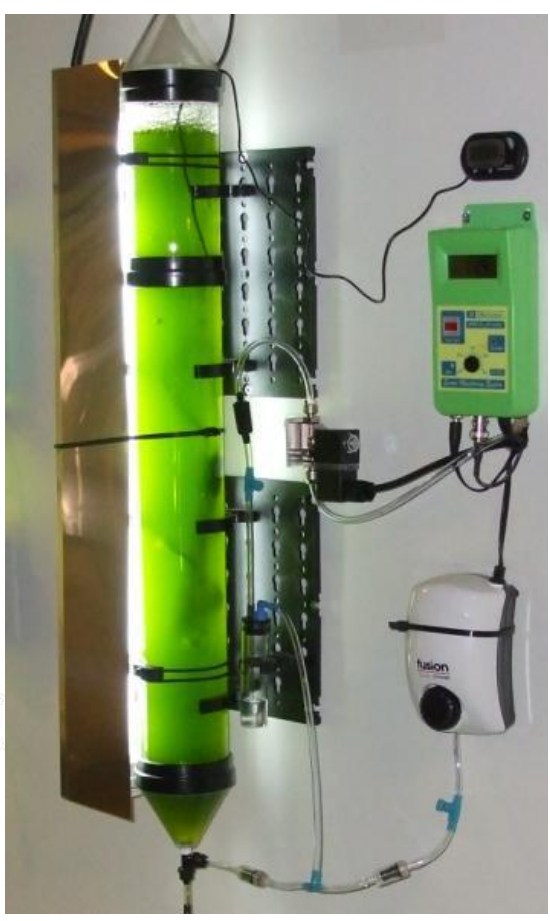

Figure 6: Laboratory PBR in use 


\subsection{Cultivation Method}

Each growth trial was limited to 5 days of growth. Upon inoculation algal samples would be taken for analysis. For the remainder of the growth period samples were taken at approximately the same time of day. The algal strains were expected to follow a typical noncontinuous batch culture growth curve. Batch growth is characterized by 4 distinct phases: lag, exponential, stationary and death. The 4 phases are depicted in Figure 7 and briefly explained below.

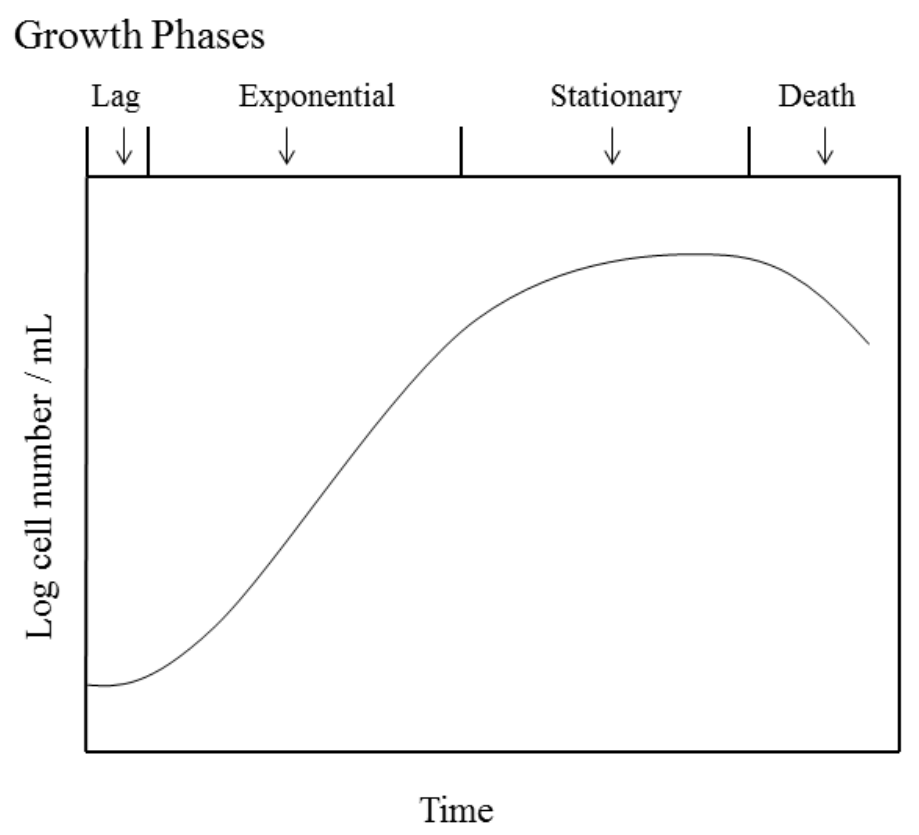

Figure 7: Typical batch culture growth curve (Adapted from Shuler and Kargi, 2002)

1. Lag: Immediately after inoculation the culture experiences a lag phase as it acclimates to the new environmental conditions.

2. Exponential: After the culture has fully adapted to the batch conditions the culture begins reproducing exponentially. This is the optimum growth seen throughout the growth cycle, and the cell population doubles at regular time intervals, known as the doubling time $\left(\mathrm{t}_{\mathrm{d}}\right)$. 
3. Stationary Phase: The stationary phase begins after exponential growth decelerates and the microorganism population is maintained. At this point the culture has reached its maximum population. At stationary phase the growth rate is equal to the death rate, and the population is held constant.

4. Death Phase: The death phase occurs once the maximum population has been supported for a period of time and the culture begins to die faster than it can reproduce. Usually nutrient depletion or toxic product accumulation causes the microorganism population to decline (Shuler and Kargi, 2002).

\subsubsection{Maintaining Inoculum}

In order to begin batch growth for each trial, algal inoculum was maintained throughout the study. Chlorella and Tetraselmis inoculum were grown in two 2 liter Erlenmeyer flasks. The idea in maintaining the culture inoculum was to keep each strain in a subdued yet healthy condition. The photoperiod was 1:1, at 12 hours of light and 12 hours of dark. Ambient air was constantly diffused into the media to provide agitation and minimal $\mathrm{CO}_{2}$. In this way each strain grew slowly and after a week of inhibited growth the culture was ready for inoculation. The goal was to have each strain at a transmittance of $40 \%$ for inoculation.

\subsubsection{Aseptic Techniques}

All twelve PBRs were taken apart and sanitized before inoculation. All other equipment in contact with the algal solution was also cleaned including the submersible heaters, the $\mathrm{pH}$ probes, the thermometers, and the algal sampling ports. A phosphoric acid solution (Star San, Five-Star, Commerce City, CO) was used for all equipment sanitation. Maintaining aseptic culturing techniques was essential to avoid contamination and culture crashes. 


\subsubsection{Inoculation Ingredients}

Each PBR had a holding volume of $2.25 \mathrm{~L}$, however the displacement caused by the submersible heater, $\mathrm{pH}$ probe and thermometer yielded an operating volume of 2.0L. In addition, two inches of head space was required to accommodate the algal uproar upon gas dosing. Beginning inoculation, $200 \mathrm{~mL}$ of algal solution at a transmittance of $40 \%$ was used. The remaining $1800 \mathrm{~mL}$ was filled with distilled water. Distilled water was used for Chlorella, while Tetraselmis required a salt water additive called Instant Ocean. Salt water was made with distilled water and Instant Ocean to an achieved specific gravity between $1.020-1.024$ at $25^{\circ} \mathrm{C}$. Schultz Plant Food Plus provided the necessary nutrients and the nutrient breakdown is seen in Table 1. Liquid plant food of was administered in doses of $1.5 \mathrm{~mL}$ per PBR. This was the only nutrient supply for the duration of the growth period besides the gas dosing. The photoperiod was set at 2:1 resulting to 16 hours of light and 8 hours of dark. Once all twelve PBRs were inoculated, the growth period began and the first samples were collected for analysis.

Table 1: Liquid Macro and Micro Nutrients, 10-15-10

\begin{tabular}{|c|c|}
\hline \multicolumn{2}{|c|}{ Schultz Plant Food Plus } \\
\hline Nutrient Constituents & Percent, \% \\
\hline $\begin{array}{l}\text { Total Nitrogen } \\
\text { Ammoniacal Nitrogen, 1.6\% } \\
\text { Nitrate Nitrogen, O.2\% } \\
\text { Urea Nitrogen, 8.2\% }\end{array}$ & 10 \\
\hline Available Phosphate $\left(\mathrm{P}_{2} \mathrm{O}_{5}\right)$ & 15 \\
\hline Soluble Potash $\left(\mathrm{K}_{2} \mathrm{O}\right)$ & 10 \\
\hline Iron $(\mathrm{Fe})$ & 0.10 \\
\hline Manganese $(\mathrm{Mn})$ & 0.05 \\
\hline Zinc $(\mathrm{Zn})$ & 0.05 \\
\hline
\end{tabular}

\subsubsection{Sample Collecting and Culture Monitoring}

Samples for analysis were collected daily throughout the 5 day growth period. Upon analyzing the samples on the fifth and final day, the PBRs were taken apart, sanitized and put back together for the proceeding growth trial. Daily monitoring of temperature and $\mathrm{pH}$ were 
performed to ensure no adverse effects on microalgae growth from these two variables, as well as preserving consistency among sample replicates.

\subsubsection{Gas Treatments}

Pure $\mathrm{CO}_{2}$ was used as the control for cultivating both algal strains. Flue gas was purchased from Praxair and the composition was meant to imitate coal-fired flue gas. The flue gas composition can be seen in Table 2.

Table 2: Flue Gas Composition

\begin{tabular}{|c|c|}
\hline Flue Gas Constituents & Concentration \\
\hline Carbon Dioxide $\left(\mathrm{CO}_{2}\right)$ & $14 \%$ (mole percent) \\
\hline Nitric Oxide $(\mathrm{NO})$ & $100 \mathrm{ppm}$ \\
\hline Sulfur Dioxide $\left(\mathrm{SO}_{2}\right)$ & $300 \mathrm{ppm}$ \\
\hline Nitrogen $\left(\mathrm{N}_{2}\right)$ & balance \\
\hline
\end{tabular}

\subsection{Quantifying Growth Kinetics}

There are multiple ways to quantify microorganism growth and each method has its advantages and disadvantages. Three methods were used to model the growth kinetics including cell counting, mass determination by volatile suspended solids (VSS) and optical density. Cell counting and optical density were performed daily throughout the growth cycle, while VSS was carried out at the beginning and end of each growth cycle.

\subsubsection{Cell Counting}

Microscopic inspection of microalgae is essential for cultivating monocultures. Quantifying the number of cells per unit volume is difficult, however necessary to verify culture purity. The difficulty arises in counting the microalgae cells because it is subject to human error and is labor intensive. A microscope (Motic, BA310) was used for sample inspection and cell counting. Duplicate cell counts for each sample were performed to obtain an average cell count per sample per day. A hemocytometer was used to count the number of cells. A hemocytometer 
has a counting chamber defined by a known depth and a grid with known surface area. The depth is the space between the grid surface and the underside of the cover slip and the standard depth is $0.1 \mathrm{~mm}$. Using the specified hemocytometer cover slip is important to maintain the intended chamber volume because the aqueous sample relies on capillary action to stay within the grid surface and therefore preserve a constant volume. The counting method was taken from Standard Methods for the Examination of Water and Wastewater, Method 10200E and 10200F (APHA, 1998) and called for counting the four corner squares and the center square seen in Figure 8 with circles. This method was used to quantify Chlorella. Tetraselmis is larger in diameter than Chlorella and very motile, therefore the method for counting Tetraselmis was slightly modified. A digital picture was taken of Tetraselmis (Figure 9) to provide a snapshot and enable cell counting. The entire grid surface area (all 25 squares composed of 16 smaller squares were counted) was used for counting because it was more representative taking into account the larger cell size and motility of Tetraselmis.

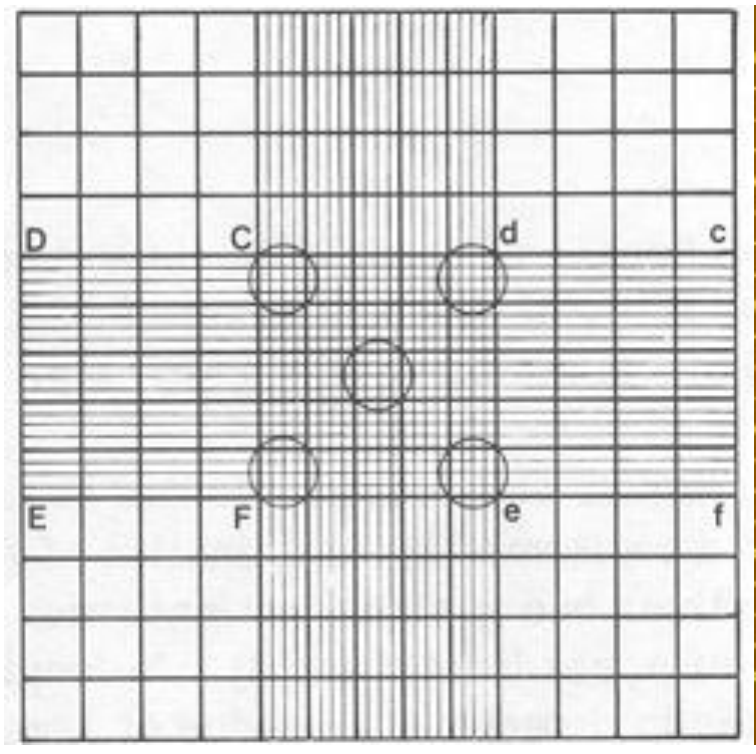

Figure 8: Standard hemocytometer grid

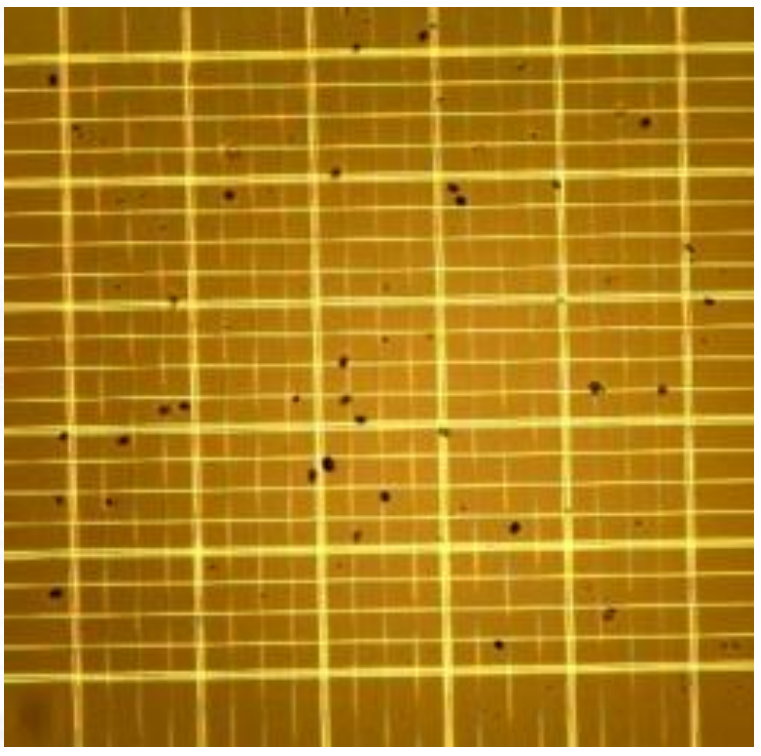

Figure 9: Counting Tetraselmis at 200x 
Before each sample was loaded for counting the hemocytometer and the cover slip were rinsed with distilled water and dried via Lense Paper. It is important to note that using Kim Wipes can scratch the glass due to its abrasiveness and was never used. Ensuring the hemocytometer and the cover slip were clean the sample was ready to be loaded. After mixing the sample well, a sterile Pasteur pipet was used to dispense the sample into the counting chamber. Caution was taken upon injecting the sample into the counting chamber because if the sample spills over the grid surface the chamber volume becomes compromised and the process must be repeated.

\subsubsection{Volatile Suspended Solids}

Measuring volatile suspend solids (VSS) provides a mass based method for determining organic content within an aqueous solution. As biomass is organic, VSS is an estimate for the quantity of biomass in an aqueous solution. These methods are commonly used for wastewater examination and the method was adapted from Standard Methods for the Examination of Water and Wastewater, Method 2540 (APHA, 1998). Total suspended solids (TSS) must be found first in order to determine VSS. TSS is the total amount of solids within an aqueous sample after the sample has been filtered through a glass fiber filter. The increase in weight from the residue retained on the filter represents TSS. VSS is the difference between the weight of dried residue and the weight of residue after ignition (also known as ash weight). The result yields an estimated biomass concentration in units of $\mathrm{mg} / \mathrm{L}$. The detailed procedure is as follows:

Filter Preparation

1. Prepare G4 glass fiber filters by rinsing with distilled water under vacuum until all water is pulled through the filter.

2. Place filter in crucible and bake in furnace $\left(550^{\circ} \mathrm{C}\right)$ for approximately 15 minutes.

3. Remove filter and crucible from furnace and place in bell jar desiccator until sample reaches room temperature.

4. Weigh filter and crucible and record A. 
5. Filter uniform aqueous sample of known volume $(\mathrm{V})$ through filter under vacuum.

6. Return filter to corresponding crucible.

7. Bake in oven at $103-105^{\circ} \mathrm{C}$ for 1 hour.

8. After baking remove from oven and allow cooling in desiccator.

9. Re-weigh dry residue, filter and crucible and record B.

10. TSS is then calculated using the equation below:

$$
T S S=\frac{B-A}{V}
$$

Equation 5

VSS

11. Place filter with dry residue and crucible in furnace at $550^{\circ} \mathrm{C}$ for 5 minutes.

12. After ignition remove from furnace and allow cooling in desiccator.

13. Re-weigh ash residue, filter and crucible and record C.

14. VSS can be calculated using the equation below:

$$
V S S=\frac{B-C}{V}
$$

Equation 6

15. Units of TSS and VSS are (mg/L) and below is the description of each recorded weight:

A: Initial filter and crucible weight, $g$

B: Dry weight of residue, filter and crucible, $g$

C: Ash weight of residue, filter and crucible, $\mathrm{g}$

$\mathrm{V}$ : Volume of aqueous sample, $\mathrm{mL}$

16. Conversions used:

$$
\begin{aligned}
& 1 \mathrm{~g}=1000 \mathrm{mg} \\
& 1 \mathrm{~L}=1000 \mathrm{~mL}
\end{aligned}
$$


VSS was performed at the beginning and end of each treatment. In this way the biomass produced over the duration of the treatment was found. There were no duplicates executed for this method due to the lack of resources, large number of samples and the extensive time required to obtain VSS data.

\subsubsection{Optical Density}

A spectrophotometer (Hach, DR3800) was used to measure the absorbance and transmittance of algal samples. The spectrophotometer seen in Figure 10 passes a light of known wavelength through an aqueous sample and measures the light entering and exiting the sample. From the measured incident and exiting light the absorbance and percent transmittance are determined. The wavelength was set at $665 \mathrm{~nm}$ because this value is the best estimate of chlorophyll content. Chlorophyll is not a direct measure of algal density, however it provides an estimated value. The advantages of such a method are the ease of use. It is quick, reliable and easy to replicate. The disadvantages include not being able to distinguish between dead and alive cells, and cellular conglomerates can give faulty readings. Similar to cell counting, optical density was measured daily in sample duplicates.

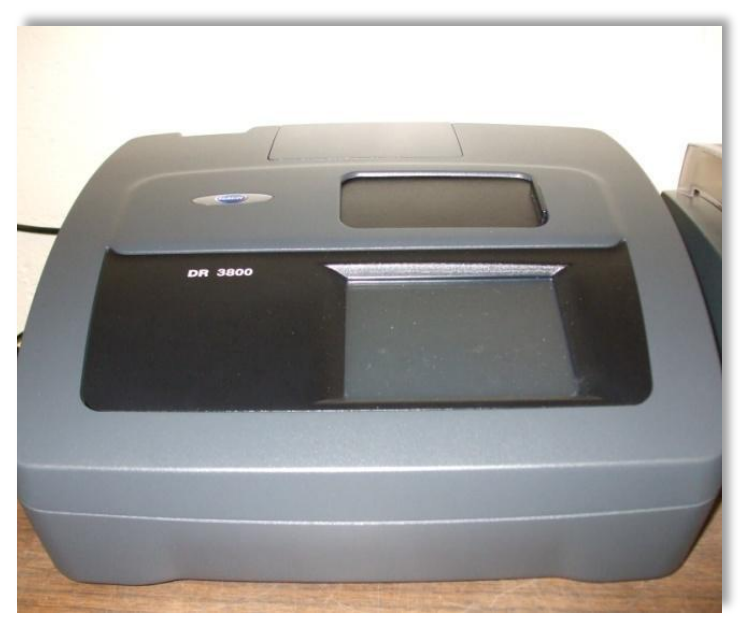

Figure 10: Hach DR3800 spectrophotometer 


\subsection{Statistics for Analysis}

Modeling the microalgae growth kinetics enabled a comparison between $\mathrm{CO}_{2}$ and flue gas treatments per algal strain. The degree of difference between cultivation methods was tested to determine if flue gas inhibited algal growth. Using Minitab 15, an unpaired t-test was used to conclude whether there was a statistically significant difference in the growth characteristics between the gas treatments for each algal strain. The t-test assumes that the sample data is Gaussian and follows a normal distribution. Biological data can never be precisely Gaussian because the normal distribution extends infinitely in the positive and negative directions. However, many times biological data follow a near bell-shaped curve and can be approximated as Gaussian. An Anderson-Darling normality test was used to ensure that the data approximated a normal distribution. Due to the small sample size of this study, the sample data could not be determined to be decisively Gaussian, rather the sample data were concluded to not be inconsistent with a normal distribution. 


\section{CHAPTER IV}

\section{RESULTS AND DISCUSSION}

\subsection{Growth Parameters Optimized}

The temperature and $\mathrm{pH}$ were maintained at optimum levels to promote the largest algal population. The average temperature and $\mathrm{pH}$ across all 3 growth trials are shown in Figure 11 and 12 respectively. Keeping the temperature and $\mathrm{pH}$ constant was important in limiting growth influences from these two variables. Persevering optimum temperature and $\mathrm{pH}$ levels, took away any influence on algal growth from such variables.

The use of heaters for Chlorella kept the temperature distribution very close to $30^{\circ} \mathrm{C}$. The error bars are plus and minus one standard deviation. The standard deviation for Chlorella $\left(1.1^{\circ} \mathrm{C}\right)$ was small compared to that of Tetraselmis $\left(2.5^{\circ} \mathrm{C}\right)$. This was due to the temperature control provided by the submersible heaters. Tetraselmis was subject to ambient temperature conditions and therefore the standard deviation is much larger due to temperature fluctuations throughout the 3 growth trials.

The pH was also kept constant as seen in Figure 12. As previously mentioned, algal growth increases the $\mathrm{pH}$ by consuming carbonic species, which in turn activated the gas dosing solenoid and administered $\mathrm{CO}_{2} /$ flue gas into the sample. The entering $\mathrm{CO}_{2}$ forms carbonic acid and causes the $\mathrm{pH}$ to decrease. This cultivation method provided the algal species with an appropriate supply of carbon, never too much and never too little. Because the flue gas contained $14 \%$ (mole percent) $\mathrm{CO}_{2}$ the flue gas was consumed far quicker compared to pure $\mathrm{CO}_{2}$ in order to fulfill the necessary carbon demand. The error bars are plus and minus one standard deviation. The standard deviation for Chlorella was 0.3 and 0.4 for Tetraselmis. Overall, the $\mathrm{pH}$ remained relatively constant. The $\mathrm{pH}$ values for both algal strains exceeded the $\mathrm{pH}$ optimums rarely. 


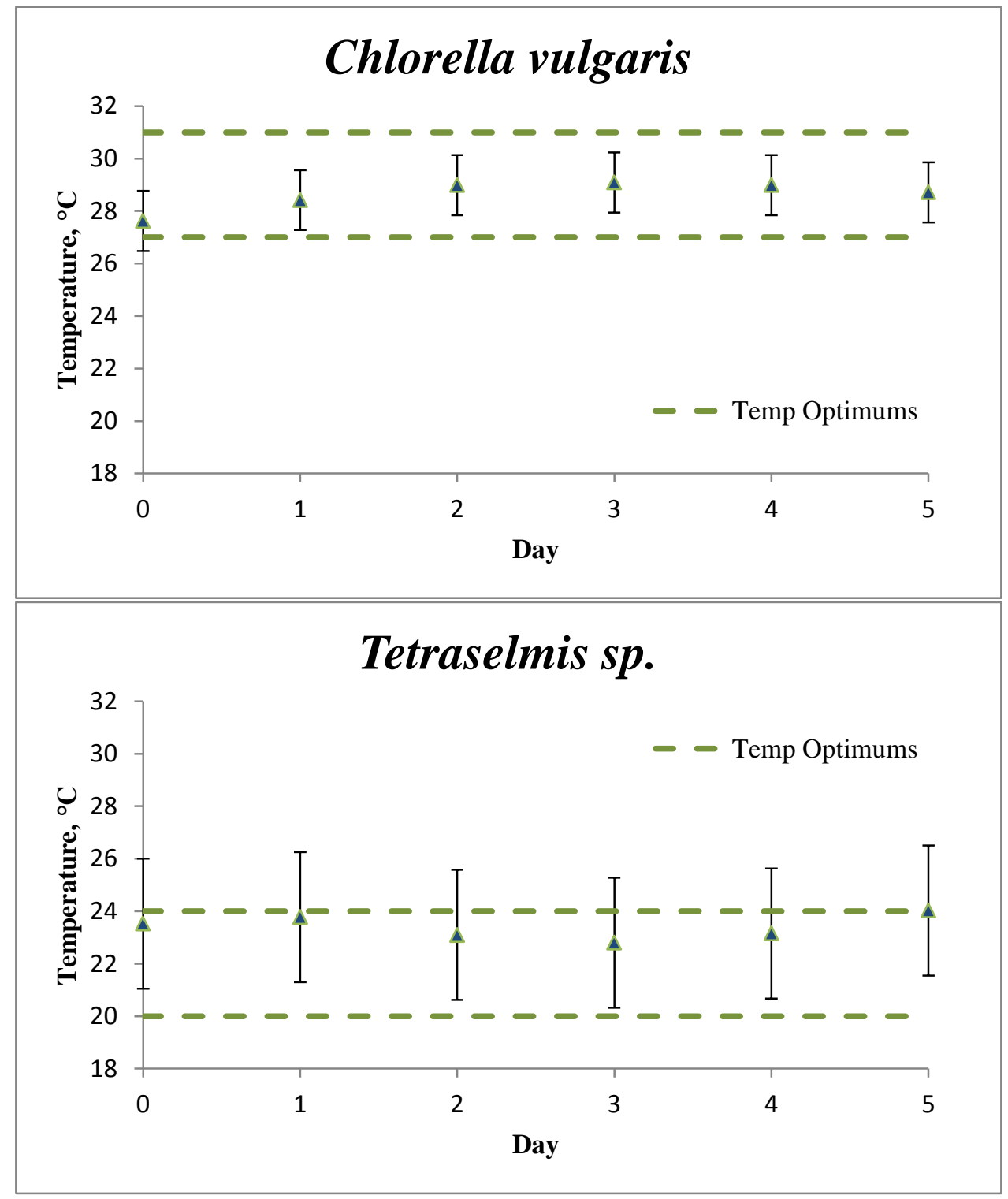

Figure 11: Chlorella and Tetraselmis mean temperature distribution from all growth trials 


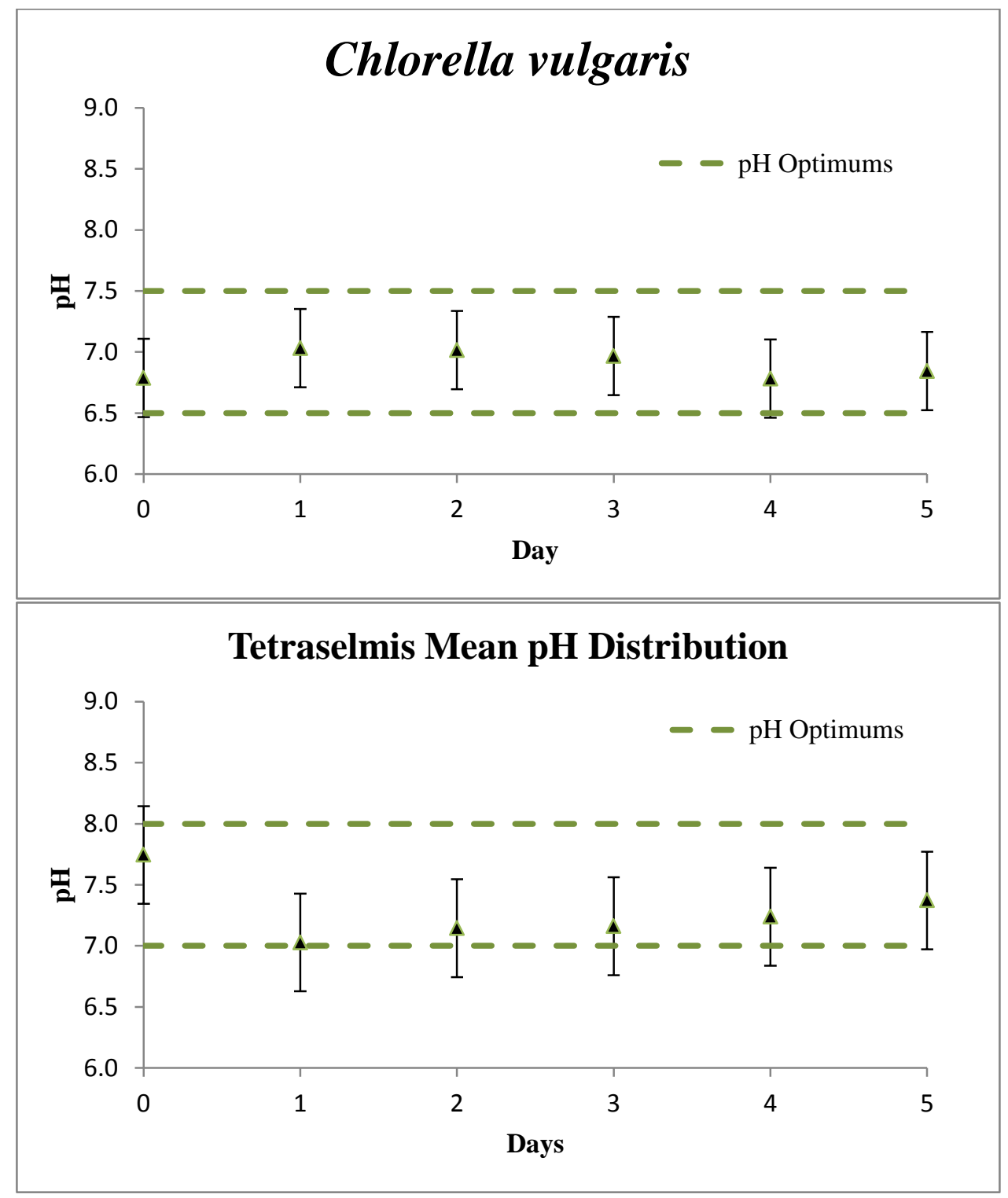

Figure 12: Chlorella and Tetraselmis mean $\mathrm{pH}$ distribution from all growth trials 
The twelve PBRs were set up in the same room as seen in Figure 13. Tetraselmis was subject to the temperature swings within the room. Chlorella was cultivated with heaters which enabled constant temperature. The $\mathrm{pH}$ was controlled as previously stated in section 4.1 Growth Parameters Optimized. Cultivating microalgae in this way provided optimum growth conditions per algal species. This was an essential element to quarantine growth variables, provide optimum environmental conditions to produce the greatest amount of biomass and enable the variable in question, gas dosing treatments to be examined.

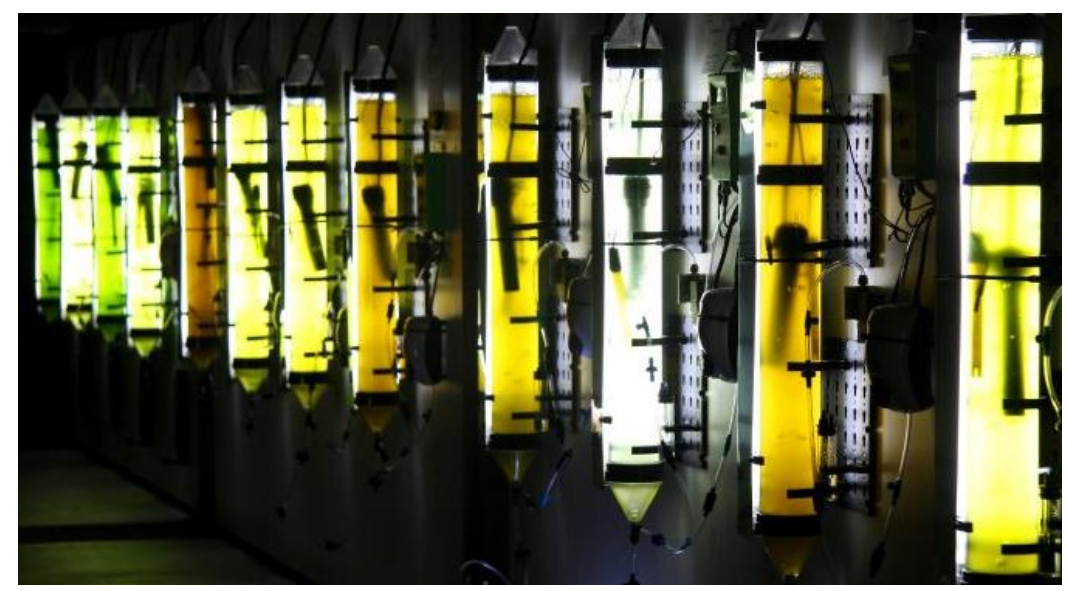

Figure 13: The twelve PBRs in use 


\subsection{Analysis Strategy}

Cell count data was used to model the growth kinetics of both algal species. Optical density was not used to model growth kinetics because absorbance and percent transmittance are arbitrary measures of analysis. Rather, cell count and optical density were correlated, so the cell count could be estimated by percent transmittance. The number of cells per mL yields an easy to understand growth curve, in which the maximum specific growth rate was calculated. The growth rates were then compared in a t-test to determine if there was a statistically significant difference in growth rates between gas treatments. The biomass produced over the growth period was also statistically compared by a t-test to conclude whether a significant difference existed among gas dosing treatments.

\subsection{Analytical Methods Correlated}

Optical density and cell counting were correlated to estimate the cell concentration from optical density. This correlation yields an easy analytical method using a spectrophotometer to estimate the number of microalgae cells per $\mathrm{mL}$. As spectrophotometry is widely used throughout the biotechnology industry, optical density is usually the most used method for determining cellular concentrations. The correlations for Chlorella and Tetraselmis under both gas treatments are seen in Figures 14 to 17. 


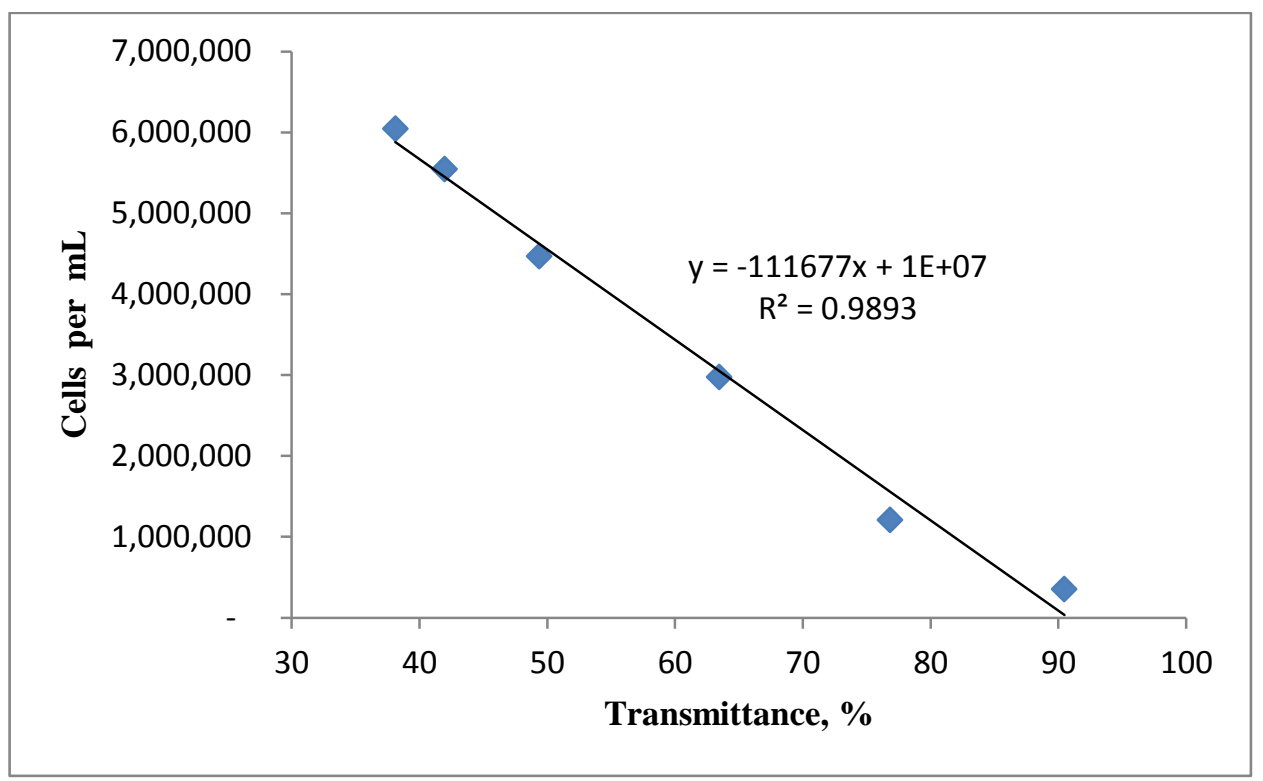

Figure 14: Correlation between analytical methods for Chlorella grown with $\mathrm{CO}_{2}$

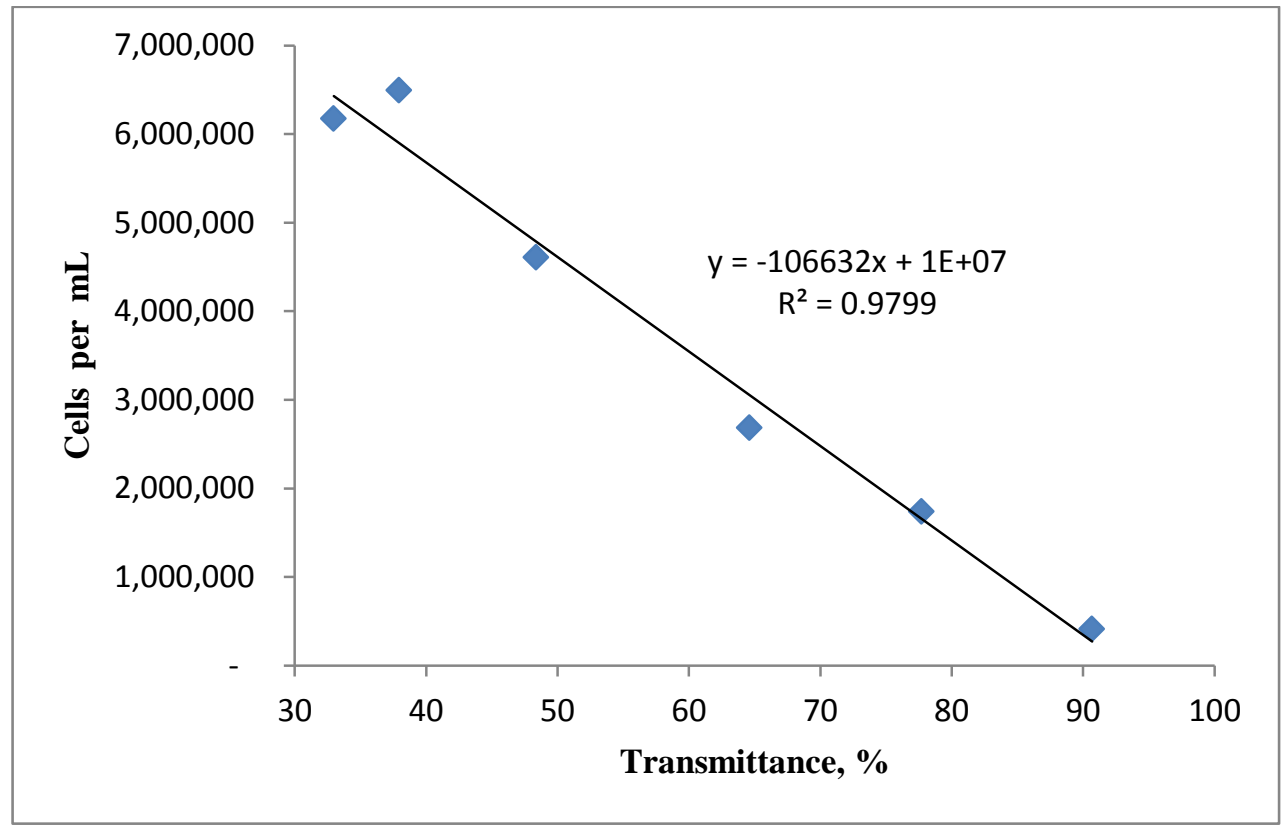

Figure 15: Correlation between analytical methods for Chlorella grown with flue gas 


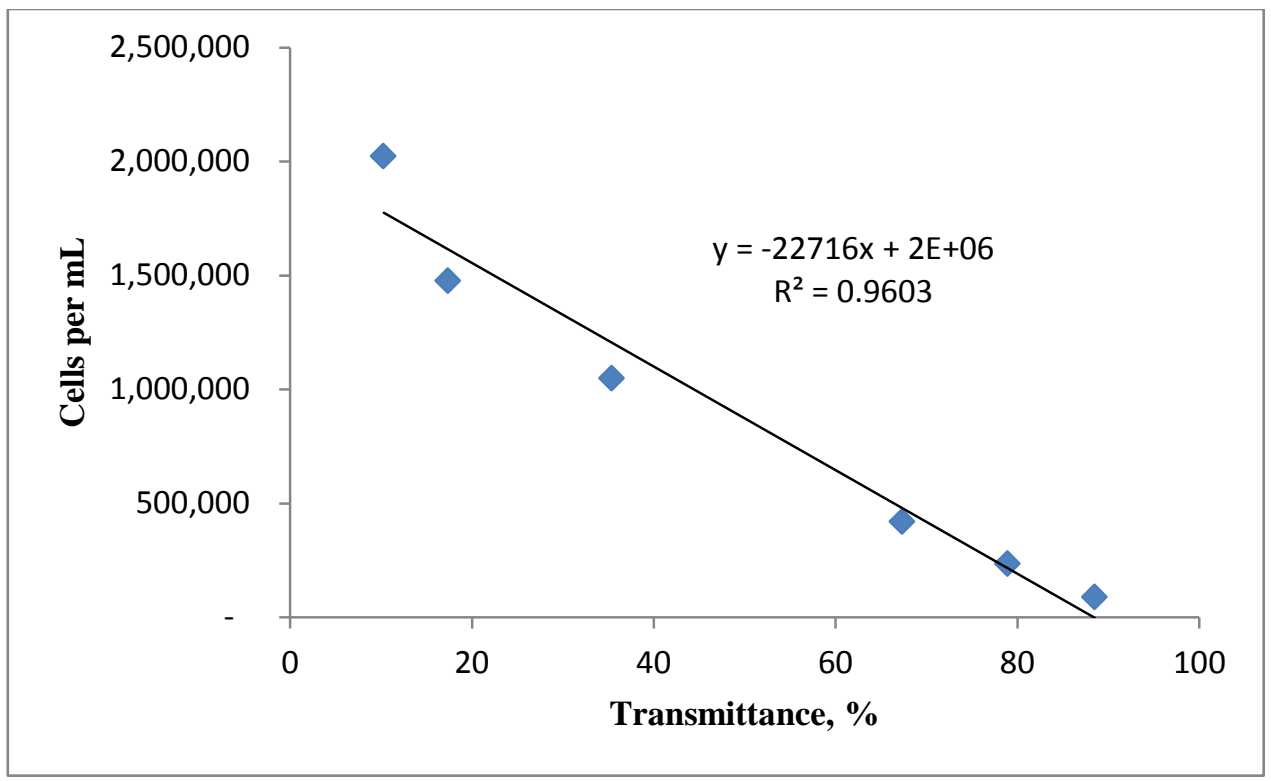

Figure 16: Correlation between analytical methods for Tetraselmis grown with $\mathrm{CO}_{2}$

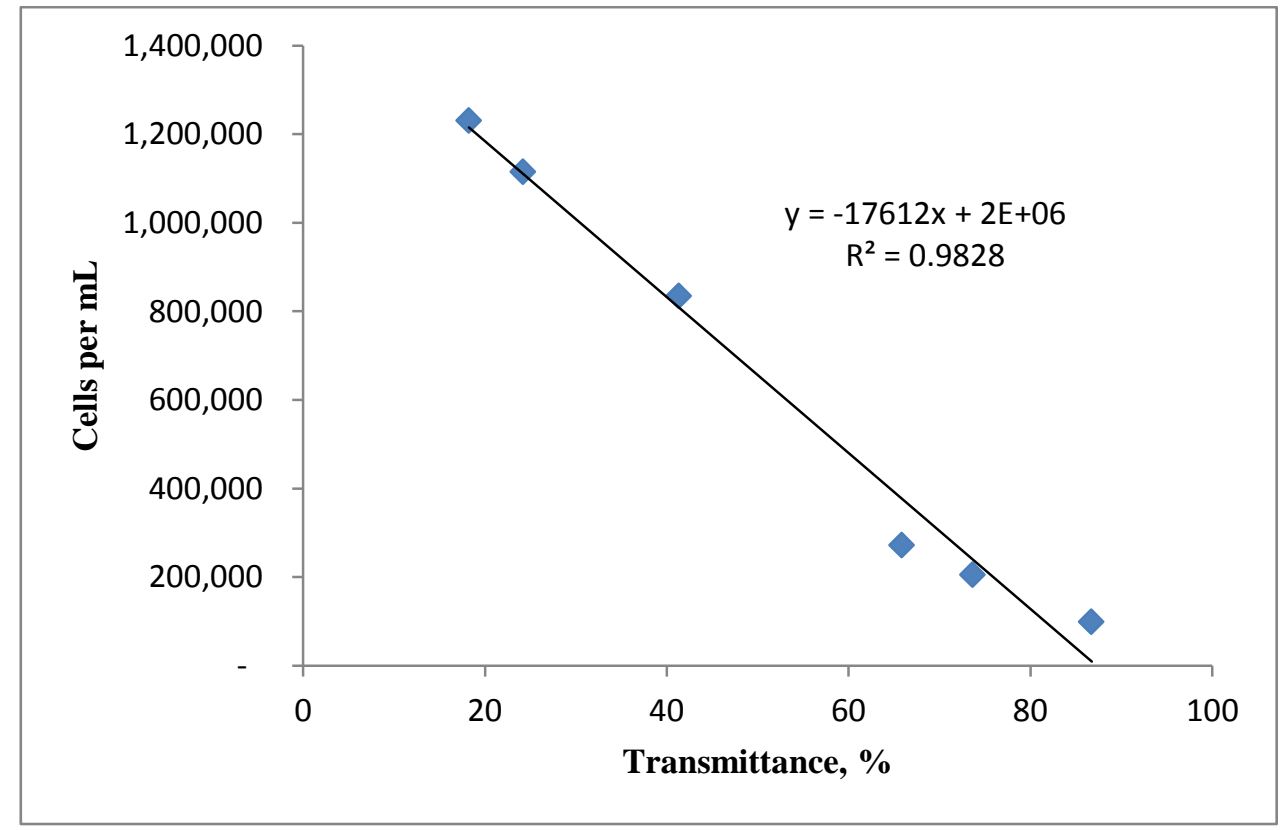

Figure 17: Correlation between analytical methods for Tetraselmis grown with flue gas 
The correlation between optical density (\% transmittance) and cells per mL yield a quick way to determine a sample cell density. The average transmittance and average cell count for all 3 trials were used for the correlation. The results are summarized in Table 3. The correlations are strongly tied with the coefficent of determination $\left(\mathrm{R}^{2}\right)$ all greater than 0.96 . Correlating cell density with absorbance yields a much more intuitive graph with a positive slope. However, using absorbance the slopes were identical per algal strain making the y-intercept the only differing aspect betweeen flue gas dosing and $\mathrm{CO}_{2}$ dosing. Therefore, percent transmittance was used to correlate cell density and Equation 7 shows the governing relationship.

$$
\frac{\text { Cells }}{m L}=(- \text { slope } * \text { transmittance })+y_{-} \text {intercept }
$$

Equation 7

As microalgae cultures grow, the cell density increases, causing a reduction in light transmitted through the sample. Therefore, the negative slope infers algal growth and increasing cell density. The gas treatment slopes for Chlorella and Tetraselmis do not differ greatly from each other, suggesting that growth between flue gas and $\mathrm{CO}_{2}$ per algal strain is not signifcantly different. A hypothesis test will conclude if the differences in growth kinetics are significant, in the upcoming section 4.6 Inferences Based on Two Sample Populations.

Table 3: Summarized relationship between cells $/ \mathrm{mL}$ and percent transmittance

\begin{tabular}{|c|c|c|c|c|}
\hline Strain & Factor & Slope (-) & Y-Intercept & $\mathbf{R}^{2}$ \\
\hline Chlorella & $\mathrm{CO}_{2}$ & 111,677 & $1.0 \mathrm{E}+07$ & 0.9893 \\
\hline Chlorella & Flue gas & 106,632 & $1.0 \mathrm{E}+07$ & 0.9799 \\
\hline Tetraselmis & $\mathrm{CO}_{2}$ & 22,716 & $2.0 \mathrm{E}+06$ & 0.9603 \\
\hline Tetraselmis & Flue gas & 17,612 & $2.0 \mathrm{E}+06$ & 0.9828 \\
\hline
\end{tabular}

\subsection{Modeling Algal Growth Kinetics}

Algal growth kinetics were modeled with cell counting data from all 3 growth trials. Due to the strong correlation between cell counting and optical density, there was no need to include 
growth curves modeled from optical density. Cell counting was used to graphically illustrate the microalgae growth kinetics. By using cell counting to model the growth kinetics, the maximum specific growth rate $\left(\mu_{\max }\right)$ was deteremined. The growth rates were then analyzed to determine if there is a signficant differnce in growth between the gas dosing treatments per algal species.

Algal biomass determination by VSS was used to quantify the amount of biomass produced over the 5 day growth period. The difference between final and initial biomass concentration yielded the dry weight of ash-free biomass produced in $\mathrm{mg} / \mathrm{L}$. Similarily to the analysis of growth rates, the biomass produced was statistically analyzed to conclude whether there was a statistically signficant difference in biomass produced between flue gas and $\mathrm{CO}_{2}$ dosing per algal strain.

\subsubsection{Growth Curves}

The growth kinetics of Chorella and Tetraselmis resembled the expected microbial growth kinetics characterized by a lag phase, exponential growth, and stationary phase. In some cases the stationary phase was never reached due to the shortened growth period of 5 days. Seeing that the stationary phase was rarely reached the death phase was never reached. The Chlorella and Tetraselmis growth curves look strikingly similar between the two gas dosing regimens. The average maximum cell concentration for Chlorella was greater for flue gas at about 6.5 million cells per mL compared to 6.0 million cells per $\mathrm{mL}$. However, the standard deviation for counting Chlorella was approximately 1 million cells per $\mathrm{mL}$, making a difference of 500,000 cells irrevelent. The error bars for Chlorella and Tetraselmis are plus and minus one standard deviation. The standard deviation was strain specific due to the different methods executed to quantify cell density. Such a large standard deviation for Chlorella was a result to the inaccuracies in cell counting. Inaccuracies such as cellular conglomerates and not being able to distinguish between living and dead cells made enumeration difficult. The maximum cell

concentration for Tetraselmis between the gas factors were nearly identical reaching 
approximately 1.2 million cells per $\mathrm{mL}$. The standard deviation for Tetraselmis was about 100,000 cells per $\mathrm{mL}$. The lower standard deviation for Tetraselmis was attributed to the larger cell size and the modified technique used for counting. The growth curves are depicted in Figures 18 to 21 for each algal strain and gas dosing treatment.

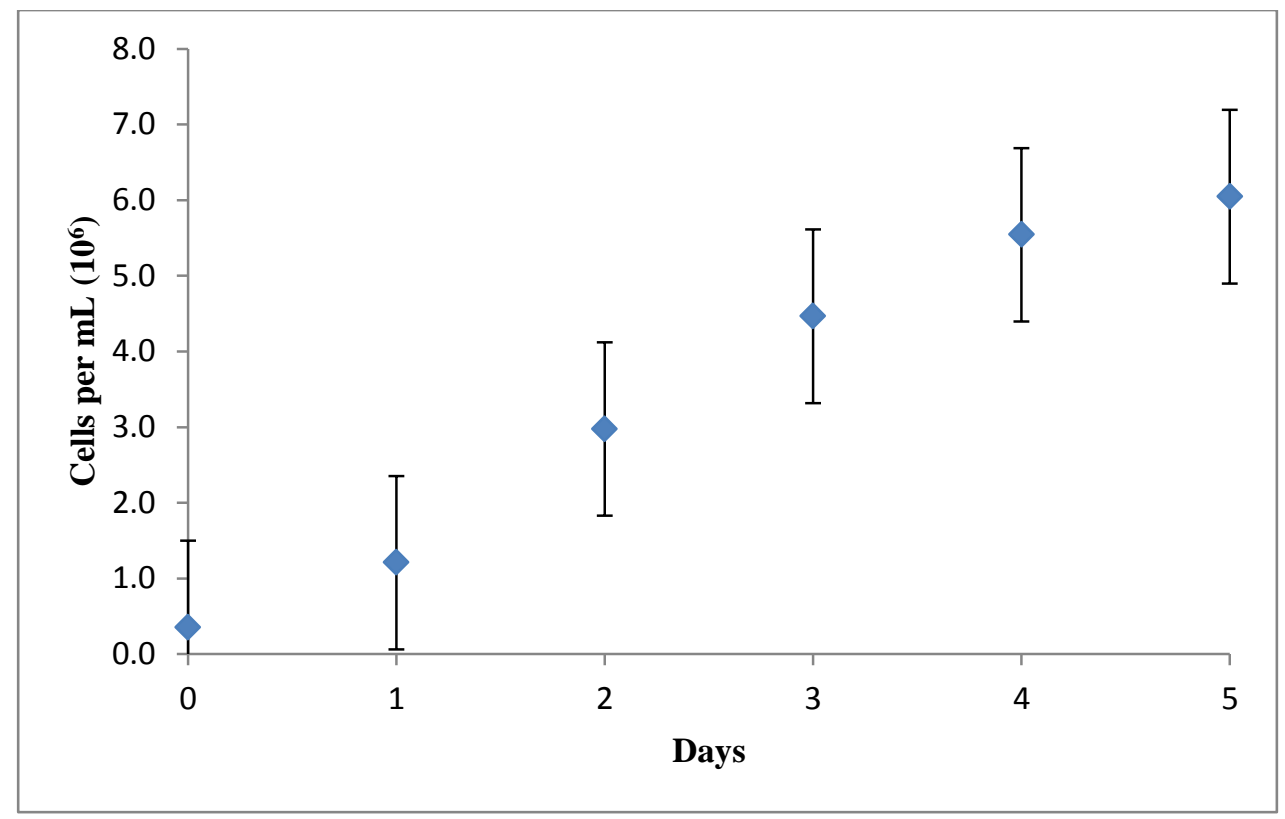

Figure 18: Growth curve for Chlorella grown with $\mathrm{CO}_{2}$

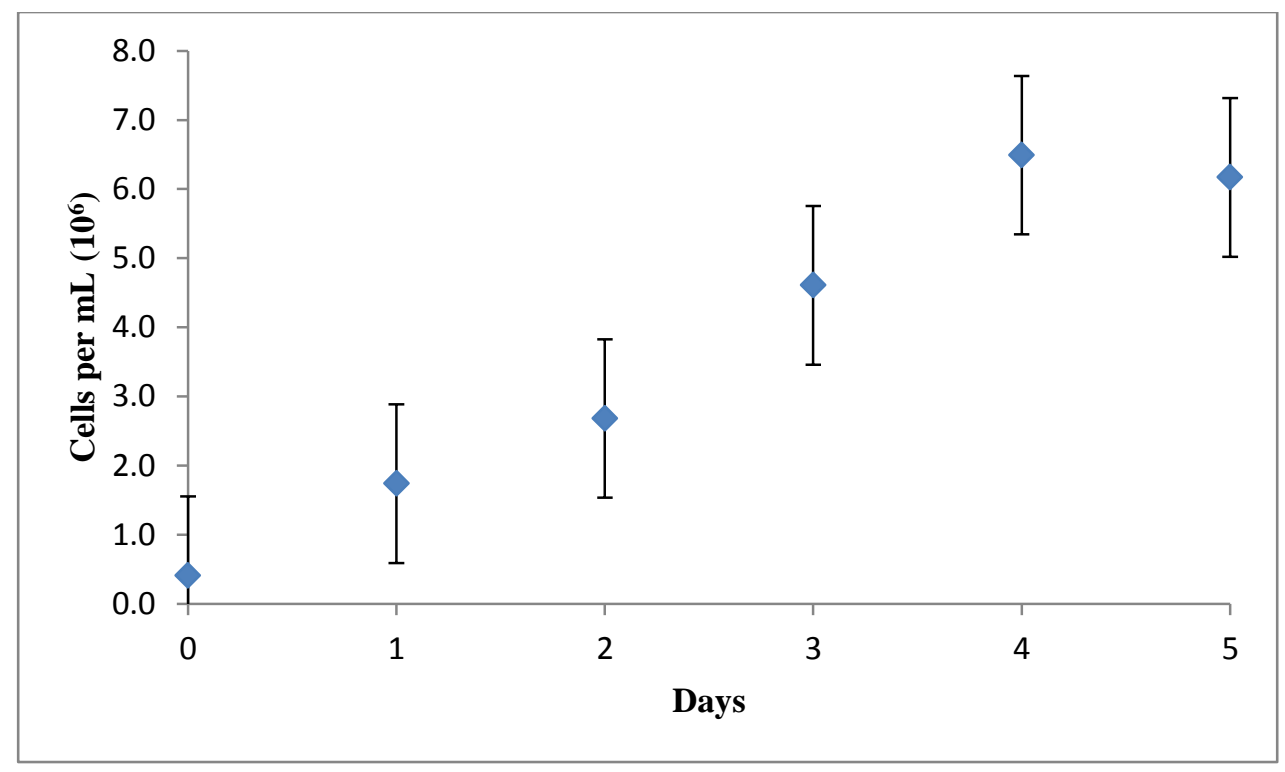

Figure 19: Growth curve for Chlorella grown with flue gas 


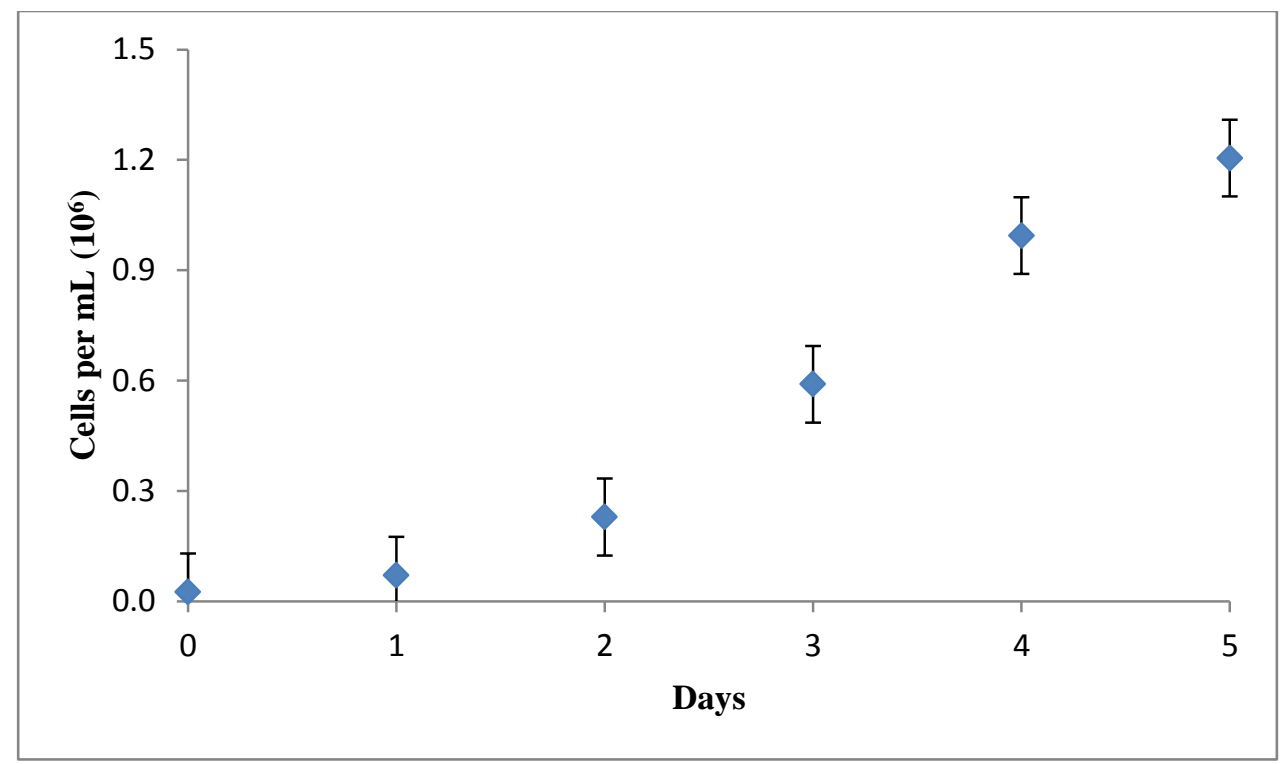

Figure 20: Growth curve for Tetraselmis grown with $\mathrm{CO}_{2}$

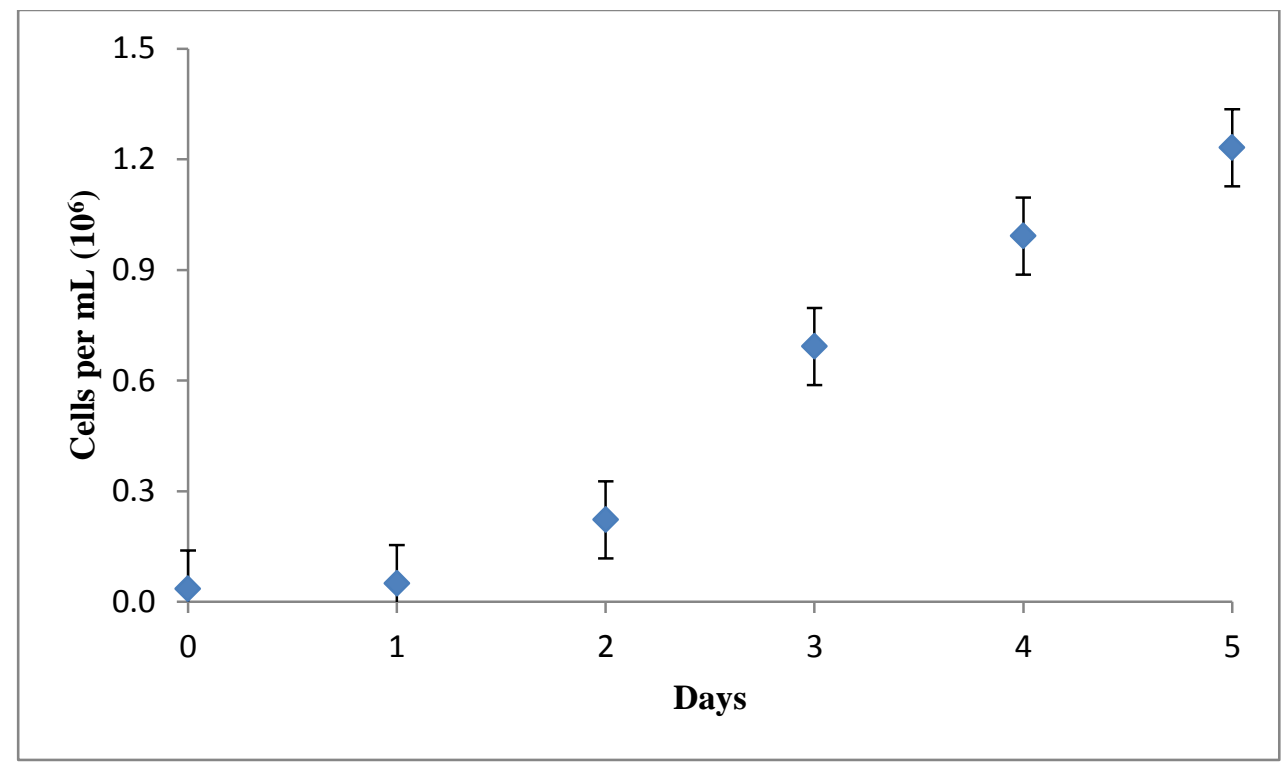

Figure 21: Growth curve for Tetraselmis grown with flue gas

\subsubsection{Maximum Specific Growth Rate}

The maximun specific growth rate was calculated by taking the natural log of the cell concentration and plotting it over time. Equation 8 shows the relationship between cell concentration $(x)$, maximum specific growth rate $\left(\mu_{\max }\right)$, and time $(\mathrm{t})$. Integrating Equation 8 
yields a linear relationship where the maximum specific growth rate is represented by the slope of the linear portion in the plot of the natural log of cell concentration verse time.

$$
\begin{gathered}
\frac{d X}{d t}=\mu_{\max } * X \\
\operatorname{Ln}(x)=\left(\mu_{\max } * t\right)+\operatorname{Ln}\left(x_{o}\right) \\
t_{d}=\frac{\operatorname{Ln}(2)}{\mu_{\max }}
\end{gathered}
$$

The resulting relationship after integration can be seen in Equation 9 and is in classic $y=$ $m x+b$ form. The linear portion for determining the growth rate was comprised of cell count data from day 0 to day 3 . These data points were chosen to maximum the specific growth rate. The data for day 4 and day 5 exhibited a deceleration in growth and would have decreased the growth rate if they had been included. Figures 22 to 25 were used to determine the maximum specific growth rates and the results are summarized below in Table 4. The growth rate of Chlorella grown with $\mathrm{CO}_{2}$ was larger than that of flue gas. The growth rates for Tetraselmis were nearly identical for flue gas and $\mathrm{CO}_{2}$ dosing. The doubling time $\left(\mathrm{t}_{\mathrm{d}}\right)$ was also determined to give a conceptual idea of the speed at which the algal strains were growing. The doubling time was calculated by rearranging Equation 9 into the form seen in Equation 10, and represents the time required for the number of cells in the population to double during exponential growth.

Table 4: Summary of maximum specific growth rates

\begin{tabular}{|c|c|c|c|c|}
\hline Strain & Factor & Growth Rate $\left(\right.$ day $\left.^{-1}\right)$ & $\mathbf{R}^{2}$ & Doubling Time (days) \\
\hline Chlorella & $\mathrm{CO}_{2}$ & 0.8488 & 0.9609 & 0.82 \\
\hline Chlorella & Flue gas & 0.7714 & 0.9175 & 0.90 \\
\hline Tetraselmis & $\mathrm{CO}_{2}$ & 1.1022 & 0.9956 & 0.63 \\
\hline Tetraselmis & Flue gas & 1.1034 & 0.9319 & 0.63 \\
\hline
\end{tabular}




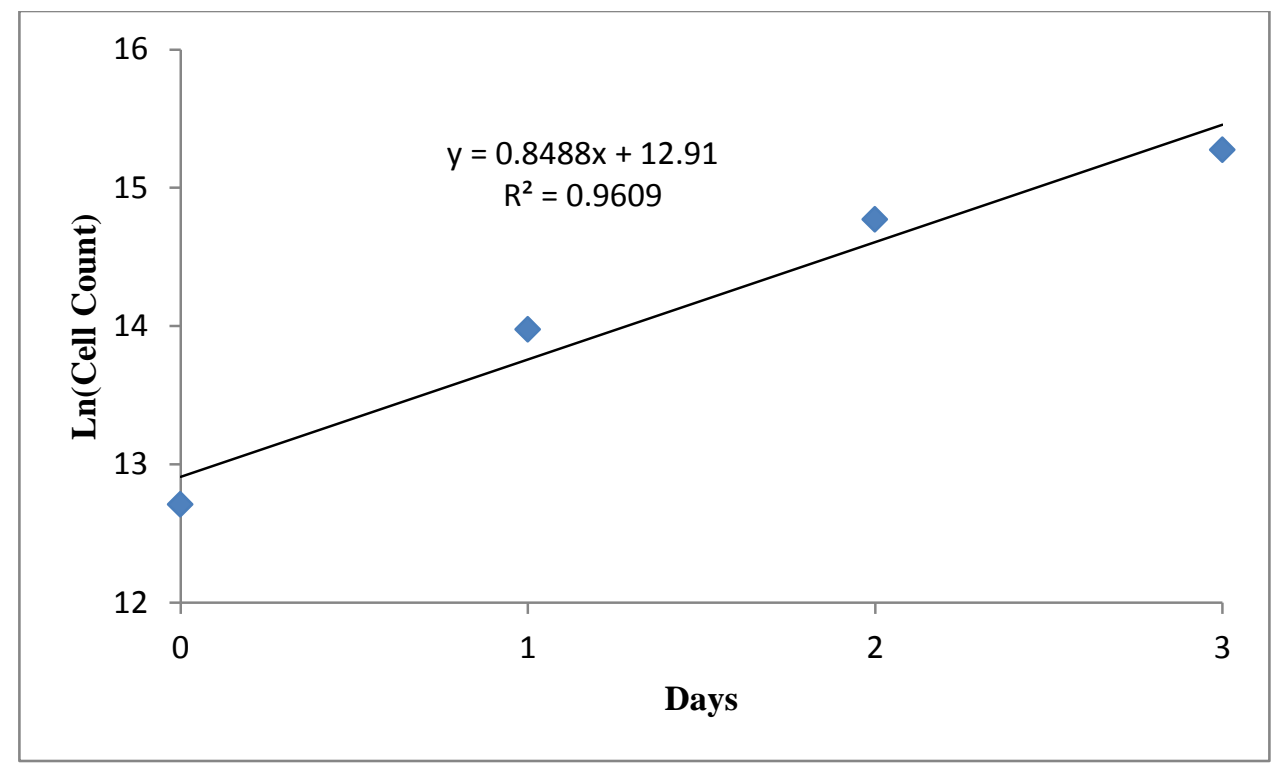

Figure 22: Maximum specific growth rate determination for Chlorella grown with $\mathrm{CO}_{2}$

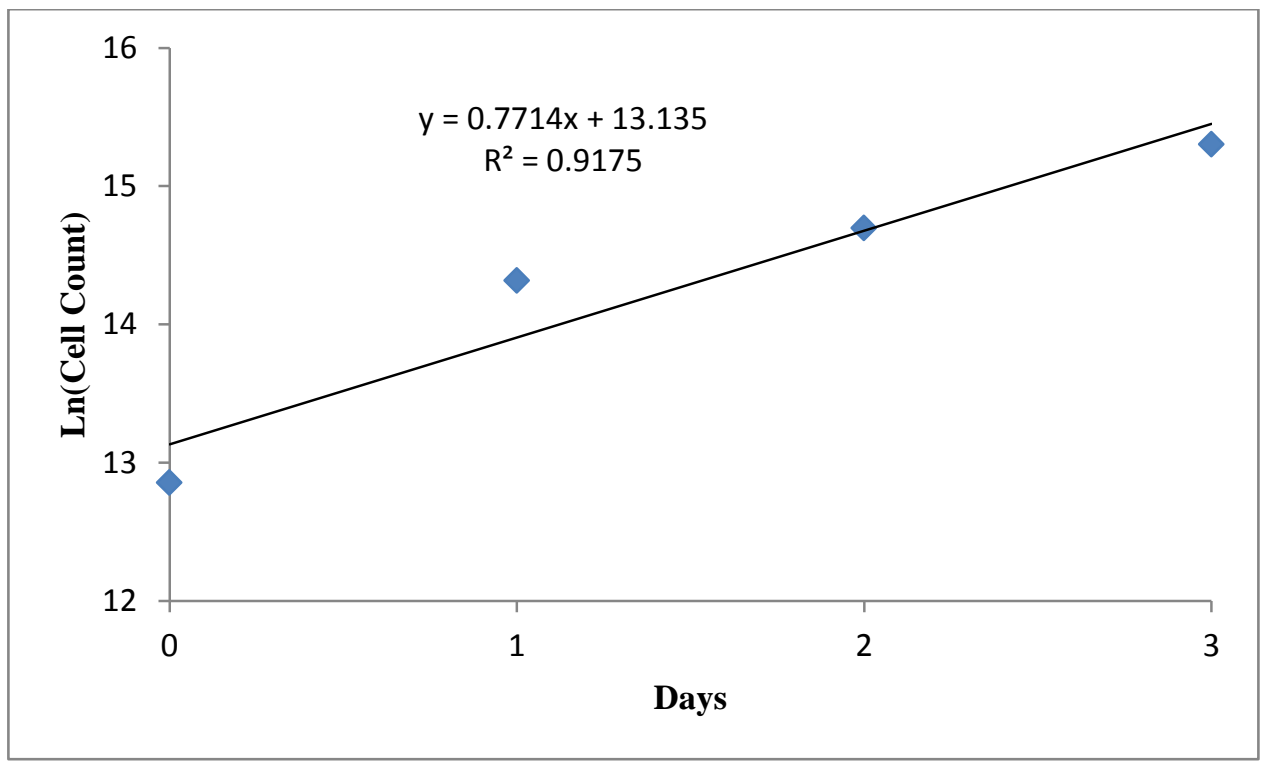

Figure 23: Maximum specific growth rate determination for Chlorella grown with flue gas 


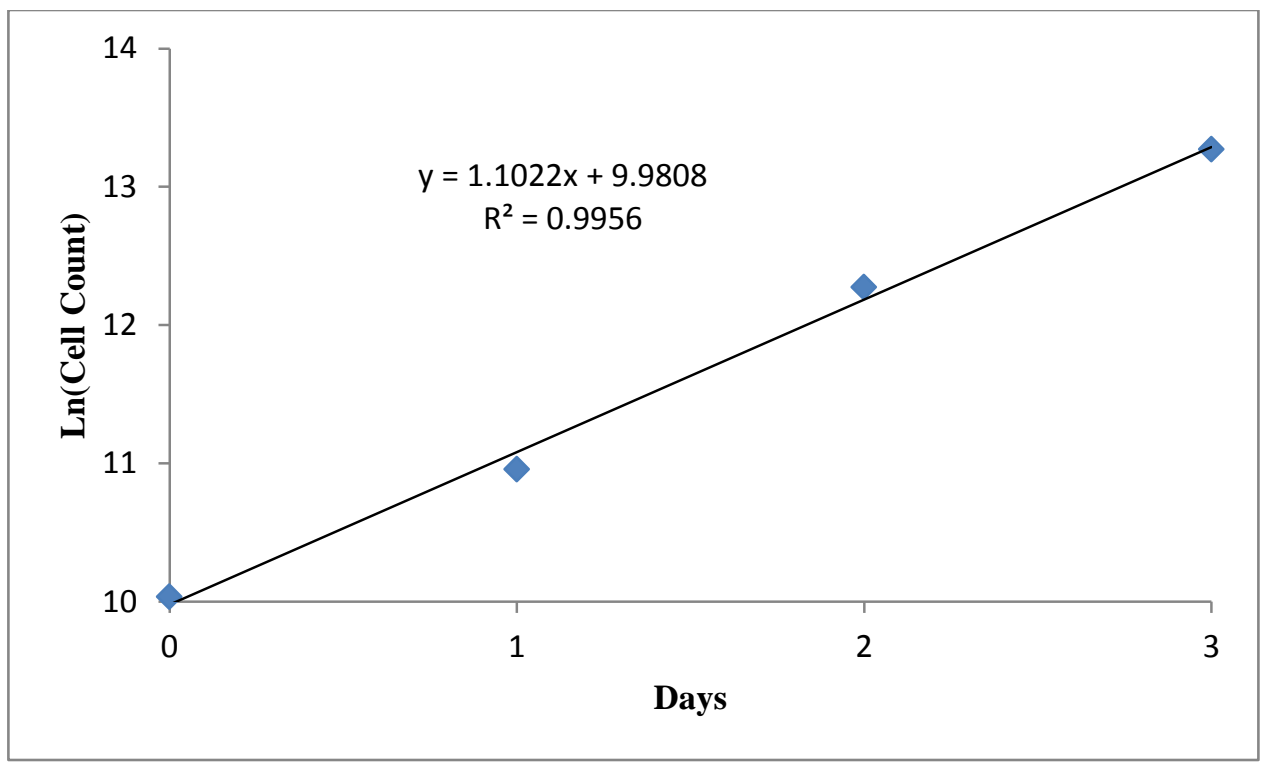

Figure 24: Maximum specific growth rate determination for Tetraselmis grown with $\mathrm{CO}_{2}$

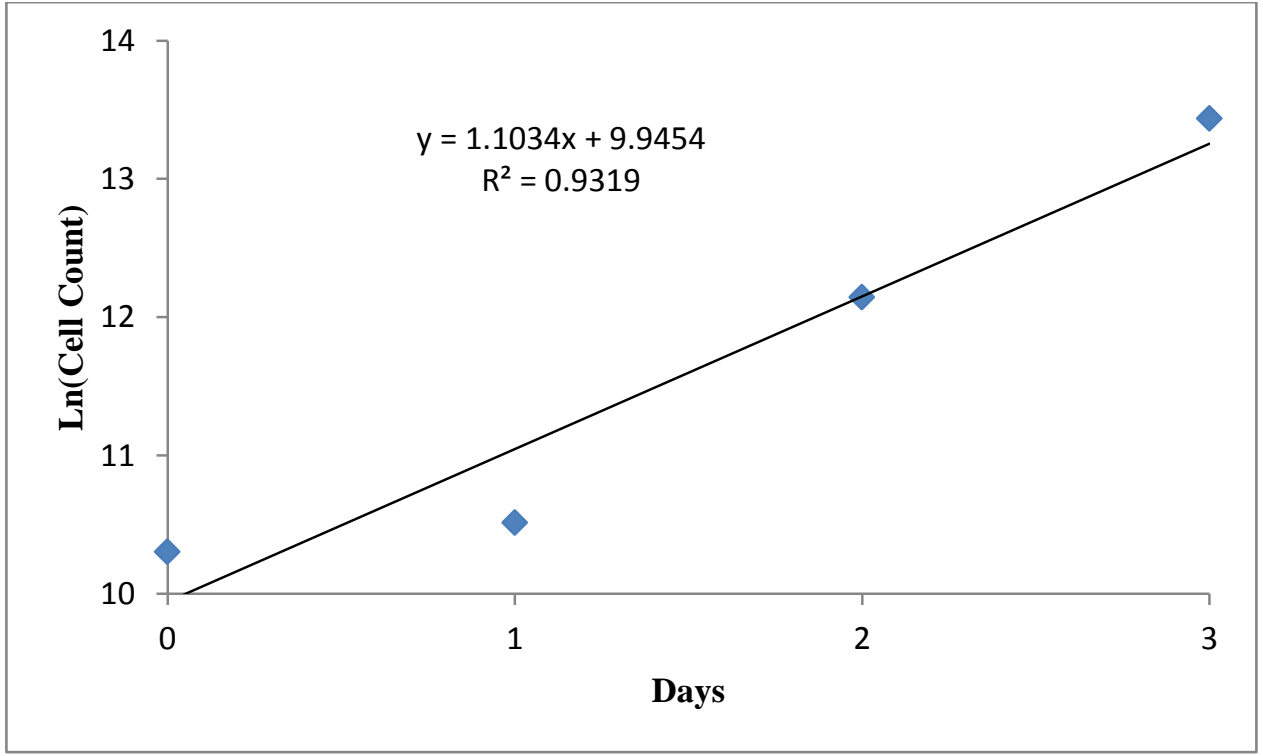

Figure 25: Maximum specific growth rate determination for Tetraselmis grown with flue gas 


\subsection{Biomass Production}

Based upon VSS measurements the total algal biomass produced was determined. Biomass production was defined as the difference between final and initial biomass quantities. Chlorella produced more biomass being grown with flue gas while Tetraselmis behaved in an opposite fashion and produced more biomass being grown with $\mathrm{CO}_{2}$. The overall biomass produced for each sample is shown in Table 5. Certain sample values were discarded due to negative biomass production values or extreme outliers.

Table 5: Mean VSS values

\begin{tabular}{|c|c|c|c|c|c|}
\hline \multicolumn{7}{|c|}{ Estimated Biomass (Dry Weight and Ash Free) } \\
\hline Strain & Factor & $\mathbf{N}$ & Initial (mg/L) & Final (mg/L) & Biomass Produced (mg/L) \\
\hline Chlorella & $\mathrm{CO}_{2}$ & 9 & 35.4 & 227.8 & 192.4 \\
\hline Chlorella & FLUE & 8 & 39.0 & 276.9 & 237.9 \\
\hline Tetraselmis & $\mathrm{CO}_{2}$ & 7 & 95.0 & 789.3 & 694.3 \\
\hline Tetraselmis & FLUE & 6 & 110.8 & 670.0 & 559.2 \\
\hline
\end{tabular}

\subsection{Inferences Based on Two Sample Populations}

An analysis on two sample populations was performed for Chlorella and Tetraselmis. A two sample t-test was carried out to determine if the average growth rates and biomass production between $\mathrm{CO}_{2}$ and flue gas treatments differed for each algal strain. Using a confidence interval of $95 \%$ and a corresponding alpha $(\alpha)$ value of 0.05 , a hypothesis test evaluated the difference in maximum specific growth rates and biomass production among the gas treatments. To ensure the validity of this test, the sample populations were first tested for normal distrubutions, a prerequiste to the t-test. 


\subsubsection{Cell Count Analysis}

Using an Anderson-Darling normality test the sample populations were tested to determine if the data followed a normal distribution. For each algal strain and gas dosing treatment, the sample population data was subjected to the following hypothesis test:

\section{Anderson-Darling Normality Test}

Null Hypothesis: $\mathrm{H}_{\mathrm{o}}: \mu$ is normally distributed

Alternative Hypothesis: $\mathrm{H}_{\mathrm{a}}: \mu$ is not normally distrubuted

Seen in Figure 26, Chlorella grown with $\mathrm{CO}_{2}$ dosing yielded a p-value of 0.656 which is greater than alpha of 0.05 . Therefore, fail to reject the null hypothesis and conclude that the sample population of Chlorella grown with $\mathrm{CO}_{2}$ is not inconsistent with a normal distribution. The Anderson-Darling normality test was performed for all sample populations and the summarized results are seen in Table 6. All the sample populations had a p-value greater than 0.05 providing that the maximum specific growth rate data per algal strain for both gas treatments could be approximated as a Gaussian distribution.

Table 6: Normality test for maximum specific growth rate data

\begin{tabular}{|c|c|c|c|c|c|}
\hline \multicolumn{6}{|c|}{ Anderson-Darling Normality Test: Specific Growth Rate } \\
\hline Strain & Factor & $\mathbf{N}$ & Mean & StDev & P-Value \\
\hline Chlorella & $\mathrm{CO}_{2}$ & 9 & 0.8488 & 0.1885 & 0.656 \\
\hline Chlorella & FLUE & 9 & 0.7714 & 0.1556 & 0.428 \\
\hline Tetraselmis & $\mathrm{CO}_{2}$ & 6 & 1.1022 & 0.1632 & 0.183 \\
\hline Tetraselmis & FLUE & 6 & 1.1034 & 0.2045 & 0.507 \\
\hline
\end{tabular}




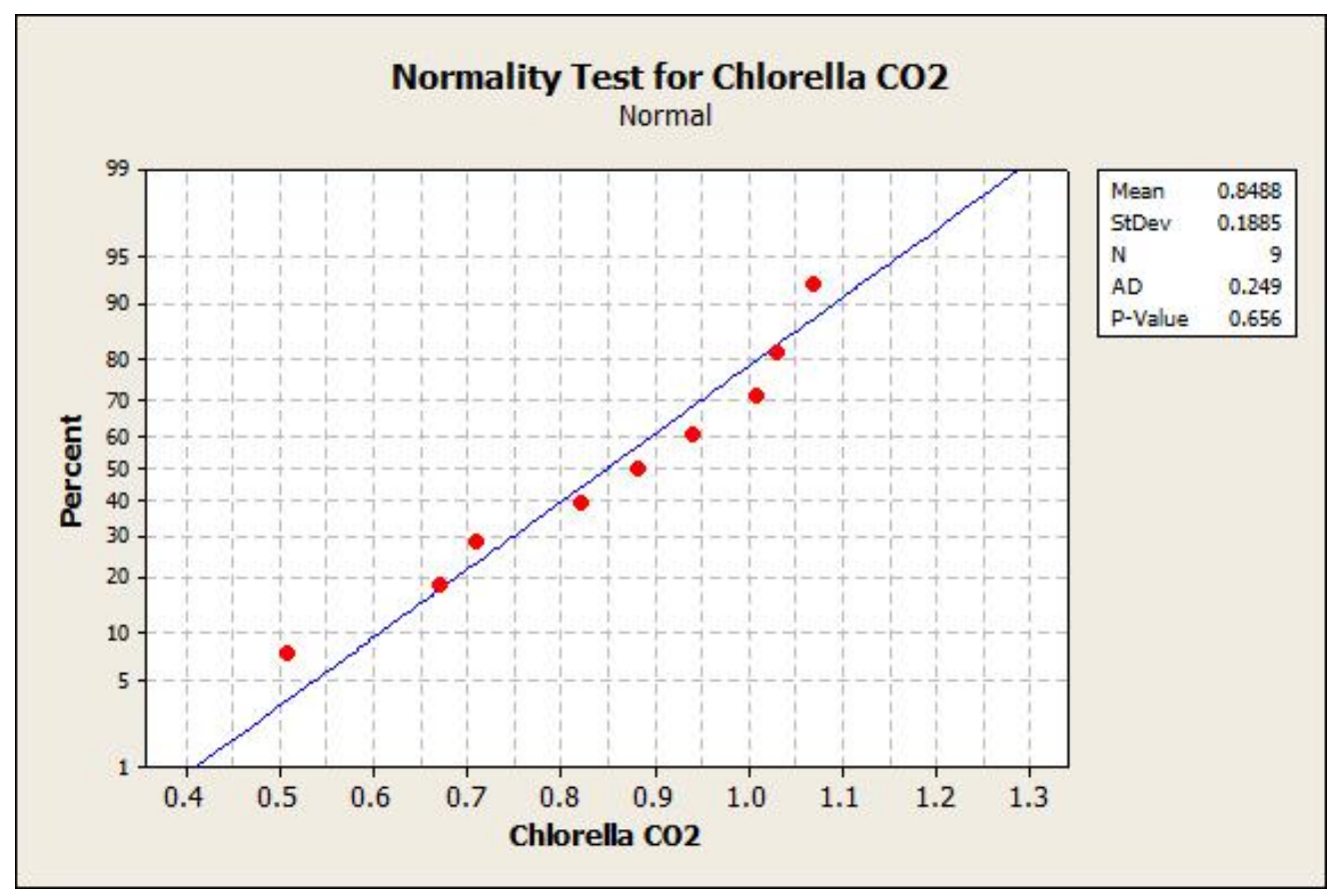

Figure 26: Maximum specific growth rate data normality test for Chlorella $\mathrm{CO}_{2}$

Confident that the small sample sizes were not inconsistent with a Gaussian distribution, a 2 sample t-test was performed to determine if the mean growth rates differed between the gas dosing treatments per algal strain. The 2 sample t-test was governed by the following hypothesises:

\section{Chlorella vulgaris}

Null Hypothesis: $\mathrm{H}_{\mathrm{o}}: \mu_{\mathrm{CO} 2}=\mu_{\mathrm{FLUE}}$

Alternative Hypothesis: $\mathrm{H}_{\mathrm{a}}: \mu_{\mathrm{CO} 2} \neq \mu_{\mathrm{FLUE}}$

Tetraselmis sp.

Null Hypothesis: $\mathrm{H}_{\mathrm{o}}: \mu_{\mathrm{CO} 2}=\mu_{\mathrm{FLUE}}$

Alternative Hypothesis: $\mathrm{H}_{\mathrm{a}}: \mu_{\mathrm{CO} 2} \neq \mu_{\mathrm{FLUE}}$ 
The resulting p-value for Chorella flue gas dosing compared to $\mathrm{CO}_{2}$ dosing was 0.357 . Again the p-value is greater than alpha $(0.357>0.05)$ so the null hypothesis can not be rejected. The maximum specific growth rates for Chlorella grown with flue gas and $\mathrm{CO}_{2}$ are not signifcantly different from one another. The p-value for Tetraselmis was even larger at 0.991 . Such a large p-value concludes that there is little doubt that maintaining the null hypothesis is false. Table 6 summarizes the t-test results for Chlorella and Tetraselmis. Overall, there is no statistically significant difference between maximum specific growth rates for the two gas dosing treatments.

Table 7: Testing the difference of growth rates between gas dosing treatments

\begin{tabular}{|c|c|c|c|c|c|c|}
\hline \multicolumn{7}{|c|}{2 Sample T-Test: Specific Growth Rate } \\
\hline Strain & Factor & $\mathbf{N}$ & Mean & StDev & SE Mean & P-Value \\
\hline Chlorella & $\mathrm{CO}_{2}$ & 9 & 0.849 & 0.188 & 0.063 & \multirow{2}{*}{0.357} \\
\hline Chlorella & FLUE & 9 & 0.771 & 0.156 & 0.052 & \\
\hline Tetraselmis & $\mathrm{CO}_{2}$ & 6 & 1.102 & 0.163 & 0.067 & \multirow{2}{*}{0.991} \\
\hline Tetraselmis & FLUE & 6 & 1.103 & 0.205 & 0.083 & \\
\hline
\end{tabular}

\subsubsection{Algal Biomass Analysis}

The same procedure was carried out to determine if there was a signifcant difference in the average algal biomass produced between gas treatmeants. First, the sample populations were tested for normality, followed by a two sample t-test.

\section{Anderson-Darling Normality Test}

Null Hypothesis: $\mathrm{H}_{\mathrm{o}}: \mu$ is normally distributed

Alternative Hypothesis: $\mathrm{H}_{\mathrm{a}}: \mu$ is not normally distrubuted

For all sample populations the p-value was greater than 0.05 , concluding that despite the small sample sizes the algal biomass data can be approximated as a normal distribution. Table 8 
summarizes the results from the individual normality tests. Figure 27 illustrates the normality test on Chlorella grown with $\mathrm{CO}_{2}$.

Table 8: Normality test for biomass produced from VSS measurements

\begin{tabular}{|c|c|c|c|c|c|}
\hline \multicolumn{6}{|c|}{ Anderson-Darling Normality Test: Algal Biomass } \\
\hline Strain & Factor & $\mathbf{N}$ & Mean & StDev & P-Value \\
\hline Chlorella & $\mathrm{CO}_{2}$ & 9 & 192.4 & 51.3 & 0.207 \\
\hline Chlorella & FLUE & 8 & 237.9 & 40.1 & 0.577 \\
\hline Tetraselmis & $\mathrm{CO}_{2}$ & 7 & 694.3 & 84.2 & 0.181 \\
\hline Tetraselmis & FLUE & 6 & 559.2 & 62.1 & 0.939 \\
\hline
\end{tabular}

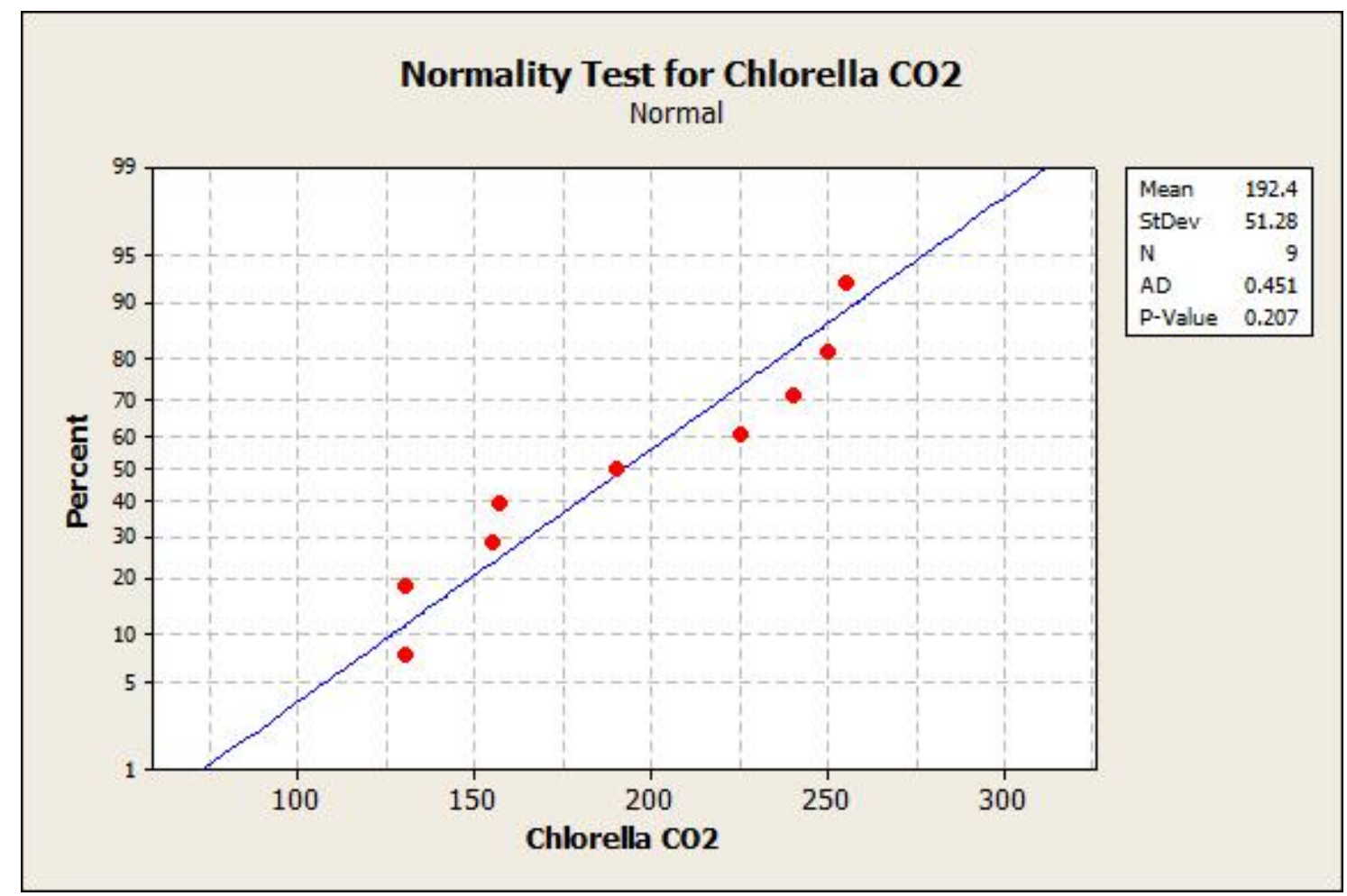

Figure 27: Normality test for biomass produced data on Chlorella grown with $\mathrm{CO}_{2}$

The two sample t-test was performed to determine if there was a significant difference in biomass produced among the gas treatments for each algal strain. The t-test was governed by the following hypothesises: 


\section{Chlorella vulgaris}

Null Hypothesis: $\mathrm{H}_{\mathrm{o}}: \mu_{\mathrm{CO} 2}=\mu_{\mathrm{FLUE}}$

Alternative Hypothesis: $\mathrm{H}_{\mathrm{a}}: \mu_{\mathrm{CO} 2} \neq \mu_{\mathrm{FLUE}}$

\section{Tetraselmis sp.}

Null Hypothesis: $\mathrm{H}_{\mathrm{o}}: \mu_{\mathrm{CO} 2}=\mu_{\mathrm{FLUE}}$

Alternative Hypothesis: $\mathrm{H}_{\mathrm{a}}: \mu_{\mathrm{CO} 2} \neq \mu_{\mathrm{FLUE}}$

Chlorella had no significant difference in the production of biomass from $\mathrm{CO}_{2}$ and flue gas treatments. A p-value of 0.06 concluded that the null hypothesis could not be rejected. The gas treatments for Tetraselmis yielded a different result with a p-value of 0.008. Since the p-value was less than 0.05 , the null hypothesis was rejected and concluded that there was a significant difference in the biomass produced between $\mathrm{CO}_{2}$ and flue gas treatments. Tetraselmis produced more algal biomass under $\mathrm{CO}_{2}$ dosing producing an average of aproximately $700 \mathrm{mg} / \mathrm{L}$ over the 5 day growth period compared to $560 \mathrm{mg} / \mathrm{L}$ produced under flue gas dosing. The difference between gas treatments for Tetraselmis biomass production ranged from 44.5 to $225.8 \mathrm{mg} / \mathrm{L}$ using a $95 \%$ confidence interval.

Table 9: Testing the difference in algal biomass production between gas dosing treatments

\begin{tabular}{|c|c|c|c|c|c|c|}
\hline \multicolumn{7}{|c|}{ 2 Sample T-Test: Algal Biomass } \\
\cline { 1 - 5 } Strain & Factor & $\mathbf{N}$ & Mean & StDev & SE Mean & P-Value \\
\hline Chlorella & $\mathrm{CO}_{2}$ & 9 & 192.4 & 51.3 & 17 & \multirow{2}{*}{0.060} \\
\hline Chlorella & FLUE & 8 & 237.9 & 40.1 & 14 & \\
\cline { 1 - 5 } Tetraselmis & $\mathrm{CO}_{2}$ & 7 & 694.3 & 84.2 & 32 & \multirow{2}{*}{0.008} \\
\hline Tetraselmis & FLUE & 6 & 559.2 & 62.1 & 25 & \\
\hline
\end{tabular}

The maximum specific growth rates across gas treatments were not significantly different, and the the difference in algal biomass production was only statistically significant for 
Tetraselmis. The similarities in growth characteristics using flue gas and $\mathrm{CO}_{2}$ strongly support the feasibility of using algal cultivation as a CCS methodology. The effects of flue gas exhibited no growth inhibition for cultivating Chlorella. Minimal growth inhibition was seen for Tetraselmis and only in the form of reducing algal biomass. 


\section{CHAPTER V}

\section{CONCLUSION}

\subsection{Experimental Conclusion}

The robust characteristics of microalgae are shown in this experiment, illustrating the ability of microalgae to adapt and survive under different carbon source treatments. Integrating microalgae cultivation alongside coal fired power plants to sequester flue gas emissions is a viable carbon capture and storage method. The additional benefit of producing biomass and providing a renewable and sustainable feedstock for biofuels further supports this CCS methodology.

\subsubsection{Chlorella vulgaris}

The differences in growth characteristics for Chlorella were not statistically significant between the gas dosing treatments. Maximum cell counts for both gas treatments reached about 6 million cells per $\mathrm{mL}$ with a standard deviation of 1 million cells per $\mathrm{mL}$. The maximum specific

growth rates were not significantly different at $0.849 \mathrm{day}^{-1}$ and $0.771 \mathrm{day}^{-1}$ for $\mathrm{CO}_{2}$ and flue gas treatments, respectively. Biomass determination by VSS further concluded no significant difference between gas treatments; producing approximately $195 \mathrm{mg} / \mathrm{L}$ of biomass for $\mathrm{CO}_{2}$ and $240 \mathrm{mg} / \mathrm{L}$ of biomass for flue gas dosing. The insignificant difference in growth characteristics between flue gas and $\mathrm{CO}_{2}$ dosing for the cultivation of Chlorella vulgaris supports the existing literature, and proves that Chlorella is a viable microalgae strain to be implemented for the abatement of $\mathrm{CO}_{2}$ emissions from coal-fired flue gas. Flue gas exhibited minimal signs of growth inhibition and the cultivation of Chlorella vulgaris from coal-fired flue gas was deemed successful. 


\subsubsection{Tetraselmis $s p$.}

The quantification of growth kinetics for Tetraselmis $s p$. gave statistically significant and insignificant differences in growth, depending on the analytical method used. Generating growth curves using cell counts yielded the same maximum cell concentration of 1.2 million cells per $\mathrm{mL}$ for both gas treatments. The maximum specific growth rates were indistinguishable at 1.1 day $^{-1}$ for both $\mathrm{CO}_{2}$ and flue gas. Biomass production by VSS proved there was a statistically significant difference in the biomass produced under $\mathrm{CO}_{2}$ and flue gas treatments. $\mathrm{CO}_{2}$ dosing produced approximately $700 \mathrm{mg} / \mathrm{L}$ of algal biomass while flue gas only produced $560 \mathrm{mg} / \mathrm{L}$. With a confidence interval of $95 \%$, the difference in biomass production between the two gas treatments ranged from 45 to $225 \mathrm{mg} / \mathrm{L}$. Although the conclusions drawn from cell counting and VSS contradict each other, Tetraselmis was able to grow under flue gas dosing. The lack of biomass production under flue gas treatments suggests $\mathrm{NO}$ and $\mathrm{SO}_{2}$ inhibit the cell development seen in the absence of biomass. The overall result supports the fact that Tetraselmis sp. could be successfully cultivated with flue gas fulfilling the carbon supply.

\subsection{Recommendations for Further Research}

Due to the statistical limitations on small sample sizes, increasing the number of samples would strengthen the analysis performed to determine the difference between gas dosing treatments. More replicates increase statistical power and provide stronger conclusions.

Modeling algal growth kinetics with VSS would provide a growth curve with units of mass $(\mathrm{mg} / \mathrm{L})$, which is more useful than the number of cells per mL. Further, VSS should be analyzed in duplicate or triplicate measures to reduce the amount variance.

Designing the experimental setup such that gas dosing is constantly purged into the growth medium would be beneficial. Analyzing the inlet and outlet gas streams would provide essential data to complete a mass balance. This would be extremely valuable to determine the amount of gas absorbed into the aqueous solution, lost due to saturation, and the amount of 
carbon utilized by the algal cells. In essence, providing a degree of mitigation effectiveness and microalgae carbon fixation efficiency is critical to implementing such a CCS strategy.

Purchasing flue gas was an ironic necessity of this experiment. Flue gas was very expensive and was depleted quickly due to the relatively small fraction of $\mathrm{CO}_{2}$ contained within the flue gas. It would be far more sensible and environmentally friendly to work in cooperation with a power plant and have a constant supply of real flue gas emissions. 


\section{BIBLIOGRAPHY}

American Public Health Association (APHA), American Water Works Association, Water Environment Federation. (1998). Standard methods for the examination of water and wastewater. (20th ed.). Washington D.C.: APHA.

Apt, E. and Behrens, W. (1999). Commercial developments in microalgal biotechnology. Journal of Phycology. Volume 35, No.2, pages 215-226.

Benemann, John (1997). $\mathrm{CO}_{2}$ mitigation with microalgae systems. Energy Conversion Managament. Volume 38, pages S475-S479.

Chisti, Y. (2007). Biodiesel from microalgae. Biotechnology Advances. 25: 294-306.

Devore, Jay (2008). Probability and statistics for engineering and the sciences, seventh edition. The Thomson Corporation, Thomson Higher Education.

Doucha, J., Straka, F. and Livansky, K.. (2005). Utilization of flue gas for cultivation of mircroalgae (Chlorella sp.) in an outdoor open thin-layer photobioreactor. Journel of Applied Phycology. Volume 17, pages 403-412.

Giere, R., Smith, K. and Blackford, M. (2006). Chemical composition of fuels and emissions from a coal + tire combustion experiment in a power station. Science Direct. Volume 85, pages 2278-2285.

Global CCS Institute (2010). The Global Status of CCS: 2010.

http://www.globalccsinstitute.com/resources/publications/global-status-ccs-2010

Grosjean, Daniel (1979). Nitrogenous Air Pollutants, Chemical and Biological Implications. Senior Scientific Advisor, Environmental Research and Technology, Inc. Ann Arbor Science Publishers.

Intergovernmental Panel on Climate Change (IPCC; 2007). Climate Change 2007: Synthesis Report.

http://www.ipcc.ch/publications_and_data/publications_ipcc_fourth_assessment_report_s ynthesis_report.htm 
International Energy Outlook (2010). International Energy Outlook 2010. July 2010.

http://www.eia.gov/oiaf/ieo/pdf/0484(2010).pdf

Kadam, Kiran (1997). Power plant flue gas as a source of $\mathrm{CO}_{2}$ for microalgae cultivation: economic impact of different process options. Biotechnology Center of Fuels and Chemicals National Renewable Energy Laboratory.

Lee, R. E. (1999). Phychology, 3rd edition. Cambridge, U.K.: Cambridge University Press.

Maeda, K., Owada, M., Kimura, N., Omata, K. and Karube, I. (1995). $\mathrm{CO}_{2}$ fixation from flue gas on coal-fired thermal power plant by microalgae. Energy Conversion and Management. Volume 36, pages 717-720.

Mehlitz, T. (2009). Temperature influence and heat management requirements of microalgae cultivation in photobioreactors. A master thesis presented to the faculty of California Polytechnic State University.

Nagase, H., Yoshihara, K., Eguchi, K., Okamoto, Y., Murasaki, S., Yamashita, R., Hirata, K. and Miyamoto, K. (2001). Uptake pathway and continuous removal of nitric oxide from flue gas using microalgae. Biochemical Engineering Journel, Volume 7, pages 241-246.

Novakovic, G., Kim, Y., Wu, X., Berzin, I. and Merchuk, J. (2005). Air-Lift Bioreactors for Algal Growth on Flue Gas: Mathematical Modeling and Pilot-Plant Studies. American Chemical Society, Ind. Eng. Chem. Res. Volume 44, pages 6154-6163.

Oilgae (2011). Flue Gas and Its Part in Global Warming. http://www.oilgae.com/algae/cult/cos/flu/flu.html

Ozkan, U., Agarwal, S. and Marcelin, G.. (1995). Reduction of Nitrogen Oxide Emissions. Division of Petroleum Chemistry, Inc. American Chemical Society, Washington, DC. Packer, Mike (2008). Algal capture of carbon dioxide; biomass generation as a tool for greenhouse gas mitigation with reference to New Zealand energy strategy and policy. Cawthron Institute, MacDiarnid Institute for Advanced Materials and Nanotechnology. 
Sawyer, C., McCarty, P. and Parkin, G. (2003). Chemistry for environmental engineering and science, fifth edition. McGraw Hill, New York.

Sheehan, J., Dunahay, T., Benemann, J. and Roessler, P. (1998). A Look Back at the U.S.

Department of Energy's Aquatic Species Program: Biodiesel from Algae. U.S. Department of Energy's Office of Fuels Development. National Renewable Energy Laboratory.

Sheeler, P. and Bianchi D. (1987). Cell and Molecular Biology, Third Edition. John Wiley and Sons, Inc.

Shuler, M. and Kargi F. (2002). Bioprocess Engineering: Basic Concepts $2^{\text {nd }}$ Edition. PrenticeHall, Inc. Upper Saddle River, NJ.

Sigee, D. (2005). Freshwater Microbiology, Biodiversity and Dynamic Interactions of Microorganisms in the Aquatic Environment. John Wiley \& Sons, LTD. Chichester, England.

South, G. R. and Whittick, A. (1987). Introduction to phychology. Oxford, U.K.: Blackwell Scientific Publications.

Spolaore, P., Cassan, C., Duran, E. and Isambert, A. (2005). Commercial applications of microalgae. Laboratory of Material Processes. The Society for Biotechnology, Japan.

Stern, N. (2007). The Economics of Climate Change: The Stern Review. Cambridge University Press, Cambridge, United Kingdom.

Tapie P. and Bernard A. (1988). Microalgae production: Technical and economic evaluations.

Biotechnology and Bioengineering 32: 873-885.

U.S. Department of Energy (DOE; 2011). Energy resources, coal. http://www.energy.gov/energysources/coal.htm

U.S. Department of Energy (DOE; 2011).Carbon Sequestration. http://www.fossil.energy.gov/programs/sequestration/index.html 
U.S. Energy Information Administration (EIA; March 2011). Emissions of Greenhouse Gases in the United States 2009. U.S. Department of Energy, Washington D.C..

U.S. Environmental Protection Agency (EPA; 2009). Clean Air Markets. http://www.epa.gov/airmarkets/trading/basics.html

U.S. Environmental Protection Agency (EPA; 2011). Greenhouse Gas Reporting Program. http://www.epa.gov/climatechange/emissions/ghgrulemaking.html

U.S. Environmental Protection Agency (EPA; 1999). Nitrogen oxides, why and how they are controlled. Clean Air Technology Center.

UTEX (2011). The Culture Collection of Algae. University of Texas at Austin. http://web.biosci.utexas.edu/utex/default.aspx

Wang, B., Li, Y., Wu, N. and Lan, C. (2008). $\mathrm{CO}_{2}$ bio-mitigation using microalgae. Applied Microbial Bitechnology. Volume 79, pages 707-718.

Woertz, I. (2007). Lipid productivity of algae grown on dairy wastewater as a possible feedstock for biodiesel. A master thesis presented to California Polytechnic State University, San Luis Obispo.

Yoshihara, K., Nagase, H., Eguchi, K., Hirata, K. and Miyamoto K. (1996). Biological elimination of nitric oxide and carbon dioxide from flue gas by marine microalga NOA113 cultivated in a long tubular photobioreactor. Journal of Fermentation and Bioengineering. Volume 82, No. 4, pages 351-354.

Zeiler, K., Heacox, D., Toon, S., Kadam, K. and Brown, L. (1995). The use of microalgae for assimilation and utilization of carbon dioxide from fossil fuel-fired power plant flue gas. National Renewable Energy Laboratory.

Zhu, Jingjing (2010). Algal Greenhouse Gas Mitigation for Coal-Fired Flue Gas. Master of Environmental Management Degree in the Nicholas School of the Environment of Duke University. 